\title{
Modulation of the Release of a Non-Interacting Low Solubility Drug from Chitosan Pellets Using Different Pellet Size, Composition and Numerical Optimization
}

\author{
Ioannis Partheniadis ${ }^{1}\left(\mathbb{D}\right.$, Paraskevi Gkogkou ${ }^{1}$, Nikolaos Kantiranis ${ }^{2}{ }^{\circledR}$ \\ and Ioannis Nikolakakis $1, *$ (D) \\ 1 Department of Pharmaceutical Technology, School of Pharmacy, Faculty of Health Sciences, Aristotle \\ University of Thessaloniki, 54124 Thessaloniki, Greece; ioanpart@pharm.auth.gr (I.P.); \\ gkogkop@gmail.com (P.G.) \\ 2 Department of Mineralogy-Petrology-Economic Geology, School of Geology, Faculty of Sciences, \\ Aristotle University of Thessaloniki, 54124 Thessaloniki, Greece; kantira@geo.auth.gr \\ * Correspondence: yannikos@pharm.auth.gr; Tel.: +30-2310997635
}

Received: 22 February 2019; Accepted: 8 April 2019; Published: 10 April 2019

\begin{abstract}
Two size classes of piroxicam (PXC) pellets (mini (380-550 $\mu \mathrm{m}$ ) and conventional (700-1200 $\mu \mathrm{m})$ ) were prepared using extrusion/spheronization and medium viscosity chitosan (CHS). Mixture experimental design and numerical optimization were applied to distinguish formulations producing high sphericity pellets with fast or extended release. High CHS content required greater wetting liquid volume for pellet formation and the diameter decreased linearly with volume. Sphericity increased with CHS for low-to-medium drug content. Application of PXRD showed that the drug was a mixture of form II and I. Crystallinity decreased due to processing and was significant at 5\% drug content. Raman spectroscopy showed no interactions. At $\mathrm{pH} \mathrm{1.2,} \mathrm{the} \mathrm{dissolved} \mathrm{CHS}$ increased 'apparent' drug solubility up to $0.24 \mathrm{mg} / \mathrm{mL}$ while, at $\mathrm{pH} 5.6$, the suspended CHS increased 'apparent' solubility to $0.16 \mathrm{mg} / \mathrm{mL}$. Release at $\mathrm{pH} 1.2$ was fast for formulations with intermediate CHS and drug levels. At pH 5.6, conventional pellets showed incomplete release while mini pellets with a CHS/drug ratio $\geq 2$ and up to $21.25 \%$ drug, showed an extended release that was completed within $8 \mathrm{~h}$. Numerical optimization provided optimal formulations for fast release at $\mathrm{pH} 1.2 \mathrm{with}$ drug levels up to $40 \%$ as well as for extended release formulations with drug levels of $5 \%$ and $10 \%$. The Weibull model described the release kinetics indicating complex or combined release (parameter ' $b$ ' > 0.75) for release at $\mathrm{pH} \mathrm{1.2,} \mathrm{and} \mathrm{normal} \mathrm{diffusion} \mathrm{for} \mathrm{the} \mathrm{mini} \mathrm{pellets} \mathrm{at} \mathrm{pH} 5.6$ (' $b$ ' from 0.63 to 0.73 ). The above results were attributed mainly to the different pellet sizes and the extensive dissolution/erosion of the gel matrix was observed at $\mathrm{pH} 1.2$ but not at $\mathrm{pH}$ 5.6.
\end{abstract}

Keywords: pellets 1; pellet diameter 2; crystallinity 3; sphericity 4; fast release 5; extended release 6

\section{Introduction}

Pharmaceutical pellets are multi-particulate drug delivery systems where the whole dose is divided into subunits with spherical shape and narrow particle size distribution within the range of 0.1 to $1.5 \mathrm{~mm}$ [1]. This multi-particulate presentation has several advantages over the tablet single-unit dosage form [2]. Pellets distribute uniformly in the gastrointestinal tract, which results in less variability in gastric emptying time, lower plasma level fluctuation, improved drug absorption, and a reduction of dose dumping. Additionally, their flowability enables processing of an automatic fast operation capsule and tableting machines, and their spherical shape makes them ideal for application of coatings [3-5].

For the preparation of pellets, extrusion/spheronization can be applied [6,7]. Product quality is controlled mainly by the composition while machine settings are less critical [8]. Microcrystalline 
cellulose (MCC) is usually part of the pellet base [9] due to its ability to retain large amounts of water in its structure, which provides elasto-plastic wet mass suitable for successful extrusion and good product quality [10-12]. However, in certain cases, incompatibilities of MCC have been reported because of its tendency to adsorb drugs on fibrils [13] and cause possible chemical interactions [14-16]. In addition, its use is obstructed by the prolonged and uncontrolled release of poorly soluble drugs [17]. An alternative is to replace part of the MCC with hydrophilic polymers, which aims to facilitate and control penetration of the aqueous dissolution medium into the pellet matrix by increasing hydrophilicity and swelling [18].

Chitosan (CHS) is a natural polysaccharide product of the deacetylation of chitin, which is a widely abundant polysaccharide. It dissolves in weakly acidic media by protonation of $-\mathrm{NH} 2$ groups, which forms a non-disintegrating gel matrix at high concentrations in water [19]. Its pharmaceutical importance as a functional excipient lies in its biocompatibility, biodegradability, and non-toxicity [20,21]. Additionally, it enhances the solubility of drugs, their permeation through the gastric mucosa, aids gastric protection due to its potent cytoprotective and healing action in gastric ulcers, and acts as a sustain-release agent [22-25]. Its effect on dissolution is influenced by the degree of deacetylation, the viscosity grade, its content in the formulations, and the drug solubility $[19,23,26,27]$. At low contents, it may act as a disintegrant, but, at high contents, it forms a hydrophilic gel, which delays drug release [28-30]. Due to its function as a 'molecular sponge', it can be used as an alternative to MCC [31]. Piroxicam (PXC) is a non-steroidal, anti-inflammatory, anti-rheumatoid, and analgesic drug $[32,33]$ assigned to Biopharmaceutical Classification System (BCS) Class II due to its poor solubility in water [34]. Since CHS is positively charged in acidic media due to the protonation of amine $[35,36]$ and PXC is cationic (pKa 5.3, Reference [35]) and is not ionized in deionized water, chemical interactions between these two are not expected and any effects on release should be due mainly to the contribution of the individual components.

The aim of this work was to prepare different CHS/MCC/PXC pellet formulations of two size classes (mini and conventional) by extruding through screens with small $(0.5 \mathrm{~mm})$ or large $(1.0 \mathrm{~mm})$ openings. Different CHS viscosity grades were initially compared and the one that prompted greater drug solubility was selected. It was expected that, due to gel formation and diffusional release, a reduction of pellet size will improve the release rate, and, thus, avoid the need to add hydrophilic excipients such as lactose [30]. However, extrusion through small orifice screens may adversely affect pellet shape and, for this reason, optimal pellet formulations with high sphericity, flowability, and instant or extended release were elucidated by applying a mixture experimental design followed by numerical optimization. The effect of processing on drug crystallinity was also examined. Since piroxicam has $\mathrm{pH}$-dependent solubility, release was tested in both acidic and deionized water [37,38]. The release mechanisms were explained by analyzing the data using the Weibull model, which presents a relatively newer kinetic approach utilizing the entire drug release profile. This provides a more thorough description of the release mechanism. This model was described originally for extended release solid forms by Bonferoni et al. (1998) and interpreted by Papadopoulou et al. (2006) [29,39].

\section{Materials and Methods}

\subsection{Materials}

Microcrystalline cellulose (MCC, Avicel ${ }^{\circledR}$ PH-101, lot 6950C) was from FMC (Cork, Ireland) and chitosan (CHS) from Primex (Siglufjordur, Island). From the supplied CHS grades: TM 3493 (viscosity

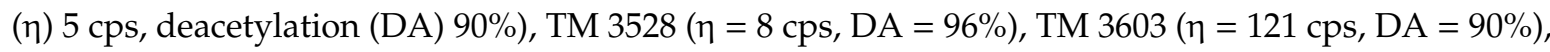
TM $3389(\eta=171 \mathrm{cps}, \mathrm{DA}=95 \%)$, and TM $3425(\eta=463 \mathrm{cps}, \mathrm{DA}=92 \%)$. The experimental CHS powders were prepared by mixing equal quantities of supplied TM 3493 with TM 3528 to give low viscosity experimental grade CHS1 (5-8 cps, DA =93\%), and TM 3603 with TM 3389 to give the medium viscosity experimental grade CHS2 (121-171 cps, DA $=92.5 \%)$. The high viscosity grade TM 3425 (463 cps, DA $=92 \%$ ) was used as received and is denoted as the experimental grade CHS3. 
Chemo Iberica S.A., Spain supplied Piroxicam (PXC). Polyvinylpyrrolidone (PVP) (K25, wt 21000$)$ was gifted from BASF (Ludwigshafen, Germany).

\subsection{Solubility of PXC in $\mathrm{pH} 1.2$ and 5.6 in the Presence of $\mathrm{CHS}$}

To determine drug solubility in $0.1 \mathrm{~N} \mathrm{HCl}$, solutions with $0.01 \%, 0.05 \%$, and $0.1 \%$ w/v CHS were prepared in $50 \mathrm{~mL} 0.1 \mathrm{~N} \mathrm{HCl}$ and excess drug $(100 \mathrm{mg})$ was added to each. A saturated drug solution in $0.1 \mathrm{~N} \mathrm{HCl}$ was also prepared for comparison. The solutions were kept at $37^{\circ} \mathrm{C}$ for $24 \mathrm{~h}$ under agitation and, prior to analysis, they were centrifuged for $10 \mathrm{~min}$ at $4500 \mathrm{rpm}$ (Labofuge 400R, Heraeus, Germany). The UV absorbance of the supernatant was measured at $334 \mathrm{~nm}$ (Pharma Spec UV-1700 Shimadzu, Kyoto, Japan) and converted to a concentration $(\mathrm{mg} / \mathrm{mL})$ from a reference curve $[\mathrm{C}=(\mathrm{Abs}+0.0085) / 0.7437]$. To measure solubility in deionized water ( $\mathrm{pH} 5.6), 100 \mathrm{mg} \mathrm{CHS}$ (non-dissolving in $\mathrm{pH}$ 5.6) were suspended in $10 \mathrm{~mL}$ deionized water and an excess drug was added. The drug-saturated solutions were kept in closed containers at $37^{\circ} \mathrm{C}$ for $24 \mathrm{~h}$ under agitation and centrifuged. The absorbance of supernatant was measured at $359 \mathrm{~nm}$ and converted to a concentration from a reference curve [C $=(\mathrm{Abs}+0.0141) / 0.4964]$.

\subsection{Preparation of Pellets}

Thirty-gram batches of CHS/MCC/PXC were blended in a Turbula ${ }^{\circledR}$ mixer (W.A. Bachofen, Muttenz, Switzerland) for $20 \mathrm{~min}$ and then transferred into a cylindrical vessel $(0.8 \mathrm{~L})$ fitted with a three-blade impeller. PVP 25 binder solution in water $(7.5 \% w / w)$ was gradually added over 5 min to give $5 \% w / w$ PVP concentration in the final dry pellets. PVP was added to the binder liquid to improve the consistency of wet mass [40]. Any further wetting liquid required was added as deionized water. The wet mass was immediately processed in a radial extruder (Model 20, Caleva Process Solutions, Dorset, UK) that was operated at $25 \mathrm{rpm}$ and fitted with a 1-mm orifice screen for the production of conventional pellets or a $0.5-\mathrm{mm}$ orifice screen for the mini pellets (both screens had 1.75-mm thickness). The extrudate was immediately processed for $5 \mathrm{~min}$ in a spheronizer (Model 120, Caleva Process Solutions) fitted with a $12-\mathrm{cm}$ diameter cross-hatch friction plate $(0.8-\mathrm{mm}$ depth grooves and pyramidal protrusions), operated at $1250 \mathrm{rpm}$ and corresponding to $7.85 \mathrm{~m} / \mathrm{s}$ peripheral velocity. The pellets were dried $\left(40^{\circ} \mathrm{C}, 12 \mathrm{~h}\right)$ in a tray oven with air circulation (Hereaus, Germany).

\subsection{Characterization of Unprocessed Materials}

\subsubsection{Particle Size}

Particle size was determined using an image processing and an analysis system comprised of a microscope (Leitz Laborux S, Wetzlar, Germany), a video camera (VC-2512, Sanyo Electric, Osaka, Japan), and software (Quantimet 500, Cambridge, UK). Powder samples dispersed in liquid paraffin were examined at $40 \times$ total magnification. A mean particle diameter was expressed as an equivalent circle diameter (diameter of a sphere with the same projected area as the particle).

\subsubsection{Pycnometric Density}

Helium pycnometry was applied (Ultrapycnometer 1000, Quantachrome Instruments, Boynton Beach, Florida, FL, USA). The instrument was calibrated using a standard $7.0699 \mathrm{~cm}^{3}$ steel ball. Samples were accurately weighed ( 3 decimals) and purged for $10 \mathrm{~min}$ before measurement. Sample volume (average of 10 runs) was measured from the displaced gas. Measurements were taken in triplicate and mean values and standard deviations were calculated.

\subsubsection{Moisture Content}

Samples of about $1 \mathrm{~g}$ were placed in an infrared radiation balance and heated at $105{ }^{\circ} \mathrm{C}$ (Halogen Moisture Analyzer HR73, Metler Toledo, OH, USA). Sample weight was automatically taken 
every $30 \mathrm{~s}$ and the process ended when the loss between two successive values was less than $0.01 \%$. Moisture content $(\mathrm{MC} \%)$ was expressed as the weight difference relative to the initial weight.

\subsection{Characterization of Pellets}

\subsubsection{Size, Shape, and Density}

Pellet size and shape were determined using an image processing and analysis system, as previously described [41]. Mean pellet diameter was expressed as an equivalent circle diameter and shape as the index $e_{R}$ (Equation (1)), which is sensitive to surface irregularity and pellet geometry, and its value increases with sphericity, which nearly reaches 0.75 for perfect spheres [42]. Examples of pellet shapes with corresponding $e_{R}$ values are shown in Figure 1.

$$
\mathrm{e}_{\mathrm{R}}=(2 \times \pi \times \text { radius }) / \text { perimeter }-\sqrt{ }\left(1-(\text { width/length })^{2}\right)
$$

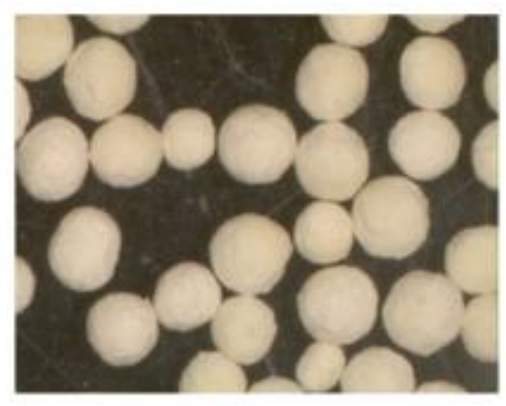

(Batch $\left.C, e_{R}=0.40\right)$

(a)

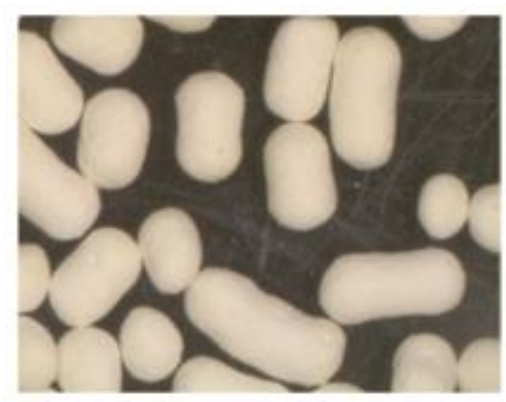

(Batch $D, e_{R}=0.17$ )

(b)

Figure 1. Images of pellet batches $C(\mathbf{a})$ and $D(\mathbf{b})$ showing different shapes.

The pycnometric density of the pellets was determined as described above for the unprocessed materials (Section 2.4.2).

\subsubsection{Packing Ability, Flowability, and Porosity}

Packing densities (bulk and tapped after 300 taps) were determined with a tester fitted with a $25 \mathrm{~mL}$ cylinder (14 mm drop, Erweka SVM 101, USP1, Heusenstamm, Germany). Carr's compressibility index $(\mathrm{CC} \%)$, equal to the volumetric change relative to tapped volume, was calculated from the density values as the index of packing ability. Flowability was estimated with an apparatus constructed according to United States Pharmacopeia [43]. Samples were transferred into a cylinder of $1.5 \mathrm{~cm}$ internal diameter and a 5-mm orifice at the center of its base. Pellets flowing through the orifice were collected on the platform of a balance (Bel Engineering MARK330, Monza, Italy) located $5 \mathrm{~cm}$ underneath the cylinder. Weight data was recorded every $0.2 \mathrm{~s}$ and transferred to a computer via an RS-232 interface. Pellet porosity was expressed as $\varepsilon \%=[1-$ (pellet density/powder density)].

\subsubsection{Physicochemical Characterization}

\section{Raman Spectroscopy}

Raman spectra were recorded to detect possible interactions between the drug and excipients using a bench top Raman spectrometer (Agility, dual band 785/1064 nm model, BaySpec, San Jose, CA, USA) and supporting software (Agile 20/20). Unprocessed powders or pellet samples were placed in standard glass vials and scanned over the range of 100 to $2700 \mathrm{~cm}^{-1}$ of Raman Shift using the laser excitation line $785 \mathrm{~nm}$, exposure time of $1 \mathrm{~s}$, and a power of incident laser beam of $150 \mathrm{~mW}$. The recorded spectra were the average of 100 runs. 
Powder X-ray Diffraction (PXRD)

Changes in the crystalline state and crystallographic characteristics of the drug were examined using PXRD (PHILIPS PW1710 diffractometer with CuK $\alpha$, Ni-filtered 1.5418 Å radiation wavelength, Phillips, Eindhoven, The Netherlands). The samples were scanned over the $3^{\circ}-43^{\circ} 2 \theta$ range, at a speed of $1.2 / \mathrm{min}$. Identification of the crystalline phases was made by comparing with published PXRD data based on the appearance and intensity of the reflections. Crystallinity was quantified as the crystallinity index $(\mathrm{CI} \%)$ expressed by the ratio of the intensity of the strongest reflectance of the drug in the pellets at $26^{\circ} 2 \theta$, relative to that of the pure drug at the same $2 \theta$. The crystallinity loss (LC\%) due to processing was obtained as a percentage of the difference between the $\mathrm{CI} \%$ of drug in physical mixtures (PM) and in pellets relative to that in PM (see Equation (2)).

$$
\mathrm{LC} \%=[(\mathrm{CI} \% \text { of drug in } \mathrm{PM}-\mathrm{CI} \% \text { of drug in pellets }) / \mathrm{CI} \% \text { of drug in } \mathrm{PM}] \times 100
$$

\subsection{In-Vitro Release}

In-vitro release of PXC was tested using the USP II Apparatus at $100 \mathrm{rpm}$ and $37 \pm 0.5^{\circ} \mathrm{C}$. Pellet samples of the experimental batches corresponding to $20 \mathrm{mg}$ of drugs were added into $900 \mathrm{~mL}$ dissolution fluid. Since PXC has $\mathrm{pH}$-dependent solubility, tests were conducted in two media including HCL $0.1 \mathrm{~N}$ (pH 1.2) and deionized water (pH 5.6). In the last case, $\mathrm{pH}$ was measured at the beginning and the end of the test and no significant change was recorded. Pellets of MCC/PXC without chitosan were also tested for comparison. Aliquots were taken at timely intervals and analyzed by UV spectroscopy (Pharma Spec UV-1700 Shimadzu, Kyoto, Japan) at $334 \mathrm{~nm}$ for pH 1.2 and $359 \mathrm{~nm}$ for $\mathrm{pH}$ 5.6.

\section{Kinetic Models}

The drug release data were analyzed using the Weibull equation [44]

$$
\ln [-\ln (1-W / W o)]=-\ln a+b \ln \left(t-t_{\mathrm{o}}\right)
$$

where $W$ is the drug released at time $t, W_{0}$ is the drug released at the end of the test, $t_{\mathrm{o}}$ is the lag time before release as determined by trial and error for best line fitting, ' $b$ ' is the constant characteristic of the shape of the release curve and the release mechanism [39], and a is a time-scale parameter defined as $a=(\mathrm{td})^{b}$ where $\mathrm{td}$ is the time required for $63.2 \%$ release.

\subsection{Experimental Design and Optimization of Compositions for Instant or Extended Release}

The influence of composition on the properties of pellets and drug release was studied separately for mini and conventional pellets. This doubled the number of experimental batches and, for this reason, the d-optimal mixture design including vertices, edge centers, centroid, and axial points was used as an efficient design applicable to constrained regions [45] (Table 1). The sum of components CHS (X1), MCC (X2), and PXC (X3) was 95\% and the remaining 5\% was PVP. Constraints were applied for CHS and MCC at $10 \%<\mathrm{X} 1, \mathrm{X} 2<80 \%$, and for the drug at $5 \%<\mathrm{X} 3<70 \%$, which provides a realistic design space. Consequently, the \% weights were transformed into a 'real' scale (Equation (4)), where their sum is 1.0, and then into L-pseudo levels (Equation (5)) where their minimum value is 0 and the maximum is 1 .

$$
\begin{gathered}
\text { Real }=\text { Actual/Total of Actuals } \\
\text { Pseudo }=(\text { Real }-\mathrm{Li}) /(1-\mathrm{L})
\end{gathered}
$$

where $\mathrm{Li}$ is the lower constraint, and $\mathrm{L}$ is the sum of lower constraints. 
Table 1. Experimental mixture design for pellet batches. The design was applied to mini and conventional pellet batches separately.

\begin{tabular}{ccccccccccc}
\hline \multirow{2}{*}{$\begin{array}{c}\text { Batch } \\
\text { Code }\end{array}$} & $\begin{array}{c}\text { Point in Design } \\
\text { Space }\end{array}$ & \multicolumn{3}{c}{ Actual Values (\%) } & \multicolumn{3}{c}{ Real Values } & \multicolumn{3}{c}{ L-Pseudo Values } \\
\cline { 3 - 10 } & CHS2 & MCC & Drug & CHS2 & MCC & Drug & CHS2 & MCC & Drug \\
\hline A & Axial & 19.38 & 54.37 & 21.25 & 0.20 & 0.57 & 0.22 & 0.13 & 0.63 & 0.23 \\
\hline B & Vertex & 80.00 & 10.00 & 5.00 & 0.84 & 0.11 & 0.05 & 1.00 & 0.00 & 0.00 \\
\hline C & Center edge & 10.00 & 47.50 & 37.50 & 0.11 & 0.50 & 0.40 & 0.00 & 0.54 & 0.46 \\
\hline D & Vertex & 15.00 & 10.00 & 70.00 & 0.16 & 0.11 & 0.74 & 0.07 & 0.00 & 0.93 \\
\hline E & Centroid & 33.33 & 35.00 & 26.67 & 0.35 & 0.37 & 0.28 & 0.33 & 0.36 & 0.31 \\
\hline F & Center edge & 45.00 & 45.00 & 5.00 & 0.47 & 0.47 & 0.05 & 0.50 & 0.50 & 0.00 \\
\hline G \# & Vertex & 10.00 & 80.00 & 5.00 & 0.11 & 0.84 & 0.05 & 0.00 & 1.00 & 0.00 \\
\hline H & Axial & 54.37 & 19.38 & 21.25 & 0.57 & 0.20 & 0.22 & 0.63 & 0.13 & 0.23 \\
\hline I & Center edge & 47.50 & 10.00 & 37.50 & 0.50 & 0.11 & 0.40 & 0.54 & 0.00 & 0.46 \\
\hline & \# This experimental batch was reproduced for testing lack of fit of the applied models. &
\end{tabular}

Multiple linear regression analysis (backward elimination) based on Scheffé polynomial (Equation (6)) was used to derive model equations between the component levels and the following pellet properties: mean diameter, shape index, dissolution efficiency at $\mathrm{pH} 1.2$, and drug release at $\mathrm{pH}$ 5.6 in $2 \mathrm{~h}$ and $8 \mathrm{~h}$. The model includes linear and interaction terms.

$$
\mathrm{Y}=\mathrm{b} 1 \mathrm{X} 1+\mathrm{b} 2 \mathrm{X} 2+\mathrm{b} 3 \mathrm{X} 3+\mathrm{b} 12 \mathrm{X} 1 \mathrm{X} 2+\mathrm{b} 13 \mathrm{X} 1 \mathrm{X} 3+\mathrm{b} 23 \mathrm{X} 2 \mathrm{X} 3
$$

Contour and trace plots were constructed from the regression equations. Contour plots show the effect of composition on a property. Each component line of the trace plots describes the effect of that component by moving along an imaginary straight path connecting the centroid of the experimental design (intersection of the three lines in the plots) to the vertex of that component in the triangle. This visualizes the effects of one single component while holding the ratio of the others constant. $p<0.05$ was the statistically significant level, and $R^{2}$ and adjusted $\operatorname{Radj}^{2}$ indicate goodness of fit.

The derived regression equations were subsequently used to optimize formulations for good sphericity ( $\mathrm{e}_{\mathrm{R}}$ in the range of $0.3-0.51$ ), maximum flowability, and fast or extended release. The criteria for fast release were set as: maximum $\mathrm{DE} \%$ and minimum td (time for $63.2 \%$ release, Weibull equation) for release at $\mathrm{pH} 1.2$, and, for extended release, they were set as: minimum $\mathrm{DE} \%$ for release at $\mathrm{pH} 1.2$, which is less than $60 \%$ release in $2 \mathrm{~h}$ and a maximum after $8 \mathrm{~h}$ release at a $\mathrm{pH}$ of 5.6. Optimization was applied for preset drug levels. The respective equations for minimization and maximization of a response di were:

$$
\begin{aligned}
\mathrm{di} & =(Y \max -\mathrm{Yi}) /\left(Y \max -Y_{\min }\right) \\
\mathrm{di} & =\left(\mathrm{Yi}-\mathrm{Ymin}_{\min }\right) /(\mathrm{Ymax}-\mathrm{Ymin})
\end{aligned}
$$

where di is the desirability function of a response ranging from 0 to $1, Y \min$ is the lowest measured value, Ymax is the highest measured value, and $\mathrm{Yi}$ is any value. $\mathrm{di}=0$ if the response value is outside the desired range and $\mathrm{di}=1$ if the response value is within the desired range. For minimization or maximization, the di varies from 0 to 1 . The overall desirability D (Equation (9)) denotes the geometric mean of the individual desirability of $\mathrm{n}$ responses.

$$
\mathrm{D}=(\mathrm{d} 1 \times \mathrm{d} 2 \times \mathrm{d} 3 \times \ldots \times \mathrm{dn}) 1 / \mathrm{n}
$$

Design Expert 8.0 (Stat-Ease, Minneapolis, MN, USA) was used to generate the experimental design, for statistical analysis, to draw the contour and trace plots, and for numerical optimization. 


\section{Results and Discussion}

The effect of chitosan grade viscosity on the solubility of piroxicam in acidic $\mathrm{pH} 1.2$ and deionized water was initially examined to select the grade that prompted greater 'apparent' solubility. The term 'apparent' is used to distinguish from the thermodynamic equilibrium solubility.

\subsection{PXC Solubility and Influence of Chitosan}

Figure 2 presents the 'apparent' solubility of piroxicam in water at both acidic $\mathrm{pH} 1.2$ and deionized water ( $\mathrm{pH}$ 5.6) measured in the presence of different CHS viscosity grades. In Figure 2a, the 'apparent' solubility of PXC at pH 1.2 (where CHS dissolves) was plotted against CHS concentration while the bars in Figure 2b show 'apparent' solubility at $\mathrm{pH} 5.6$ in the presence of suspended CHS. Due to its primarily acidic character, PXC is more soluble in basic environments [35,36]. Its measured greater solubility in CHS-free water at $\mathrm{pH} 1.2$ than at $\mathrm{pH} 5.6(0.10$, Figure $2 \mathrm{a}$, compared with $0.023 \mathrm{mg} / \mathrm{mL}$, Figure $2 \mathrm{a}, \mathrm{b})$ is attributed to its amphiphilic character that allows some ionization at $\mathrm{pH} 1.2$ (protonation of -NH2) but not at pH 5.6. From Figure 2a, it can be seen that, at $\mathrm{pH} 1.2$, the 'apparent' solubility increased remarkably from $0.10 \mathrm{mg} / \mathrm{mL}$ in CHS-free water to $0.165 \mathrm{mg} / \mathrm{mL}$ in the $0.01 \mathrm{w} / \mathrm{w}$ CHS solution. Thereafter, the increase differed for each grade. For the low viscosity CHS1, it was small and reached $0.194 \mathrm{mg} / \mathrm{mL}$ at the highest $0.1 \% w / w$ CHS while, for the medium CHS2 and high CHS3 viscosity grades, it increased exponentially. It reached 0.238 and $0.222 \mathrm{mg} / \mathrm{mL}$. Similarly, Figure $2 \mathrm{~b}$ shows that the presence of CHS as suspended polymer in deionized water also increased drug solubility, but, to a lesser extent than $\mathrm{pH} 1.2$, and the differences between the drug solubilities in the three CHS suspensions were small (0.138, 0.157, and $0.150 \mathrm{mg} / \mathrm{mL}$ for CHS1, CHS2, and CHS3, respectively).

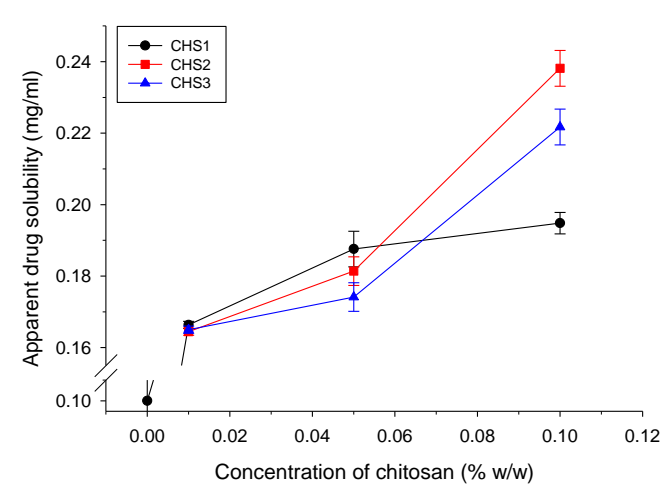

(a)

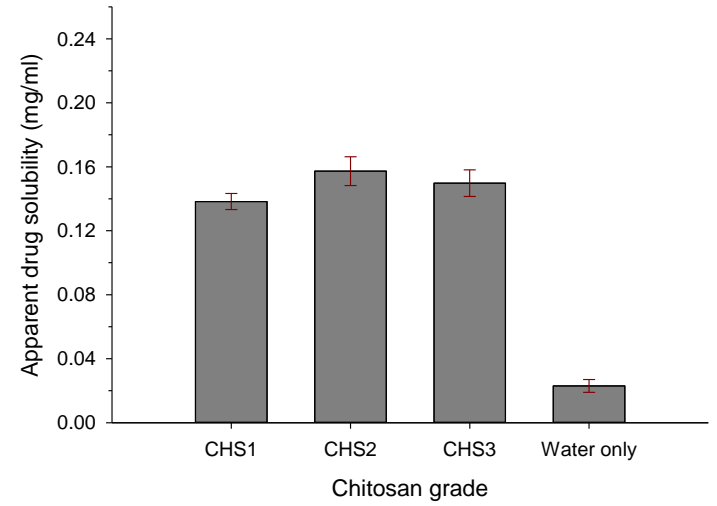

(b)

Figure 2. (a) Apparent solubility of piroxicam at $\mathrm{pH} 1.2$ in the presence of increasing concentrations of low (CHS1), medium (CHS2), and high viscosity (CHS3) chitosan grades (error bars are standard deviations, $n=3$ ). (b) Apparent solubility of piroxicam in deionized water ( $\mathrm{pH}$ 5.6) in the presence of $100 \mathrm{mg}$ chitosan suspended in $10 \mathrm{~mL}$ water.

The greater effect of CHS on 'apparent' drug solubility at $\mathrm{pH} 1.2$ compared to $\mathrm{pH} 5.6$ is attributed to the solubility of CHS at $\mathrm{pH} 1.2$ but not in deionized water (pH 5.6). At $\mathrm{pH} 5.6$, polymer fibers sorb water but do not dissolve, and, hence, only those drug molecules adsorbed onto fibers benefit from wetting, which results in limited increased solubility. On the other hand, in the acidic environment, the dissolved CHS chains form water-soluble units with the drug molecules attached to the chains, which considerably increases 'apparent' drug solubility [46]. A possible explanation for the formation of chitosan/drug water soluble units could be weak hydrogen bonding between hydroxyl groups present in the chitosan with the hydroxyl of the protonated in the acidic $\mathrm{pH}$ zwitterionic tautomer of piroxicam [47]. The greater drug solubility improvement shown by the high viscosity CHS grades may be due to network formation of the CHS chains where the CHS-PXC water-soluble units are stabilized. 
The chains of low viscosity CHS are unable to form networks due to their mobility. Therefore, the CHS2 grade that prompted higher solubility was chosen to develop CHS/MCC/PXC pellets.

\subsection{Technological Characteristics}

\subsubsection{Wetting Liquid Volume, Pellet Size, and Shape}

The measured properties of the experimental materials are given in Table 2. From Table 2, it can be seen that the experimental powders had similar median (d50) particle diameters for CHS2 $21 \mu \mathrm{m}$, for PXC $11 \mu \mathrm{m}$, and MCC $31 \mu \mathrm{m}$, and similar pycnometric densities for CHS2 $1.64 \mathrm{~g} / \mathrm{cc}$, MCC $1.69 \mathrm{~g} / \mathrm{cc}$, and PXC $1.58 \mathrm{~g} / \mathrm{cc}$. The similarity in particle diameters and densities favors good mixing and homogeneous paste formation $[48,49]$. The moisture contents of the unprocessed materials fell within the expected ranges.

Table 2. Properties of the unprocessed experimental materials.

\begin{tabular}{|c|c|c|c|c|c|}
\hline \multirow{2}{*}{ Material } & \multirow{2}{*}{$\begin{array}{l}\text { Moisture } \\
\text { Content (\%) }\end{array}$} & \multirow{2}{*}{$\begin{array}{l}\text { Particle Density } \\
\text { (g/cc) }\end{array}$} & \multicolumn{3}{|c|}{ Particle Size Distribution Parameters ${ }^{\#}(\mu \mathrm{m})$} \\
\hline & & & d10 & d50 & d90 \\
\hline CHS2 & $8.78 \pm 0.71$ & $1.64 \pm 0.01$ & 10.3 & 21.0 & 83.2 \\
\hline MCC & $5.38 \pm 0.22$ & $1.69 \pm 0.01$ & 10.7 & 31.0 & 100.6 \\
\hline PXC & $0.32 \pm 0.01$ & $1.58 \pm 0.01$ & 6.4 & 11.0 & 28.6 \\
\hline
\end{tabular}

Table 3 presents the volumes of added liquid and the paste consistencies that, after extrusion/spheronization, gave the highest sphericity for mini and conventional pellets with a mean pellet diameter and shape indexes. Batches B, F, and H with high CHS2 (80\%, 45\%, and 54.37\%) showed high consumption. Although both CHS and MCC consist of fibrils in a sponge-like structure, chitosan-rich pellets, e.g., batch B with $80 \%$ CHS2, consumed larger amounts of liquid than MCC-rich pellets, e.g., batch G with $80 \%$ MCC ( $58.0 \mathrm{~mL}$ compared to $42.0 \mathrm{~mL}$ ). However, the wet mass of batch B had low plasto-elasticity, that separated under light pressure, and gave low sphericity pellets after spheronization ( $\mathrm{e}_{\mathrm{R}} 0.27$ and 0.32 for the mini and conventional pellets, respectively, Table 3 ) with a large proportion of small-sized pellets, as reflected by the low mean diameters ( 367 and $712 \mu \mathrm{m}$, Table 3). This indicates that only part of the consumed liquid was used to form a mass suitable for extrusion, with the remainder residing loosely in the interior [31]. Batch D with the highest drug content $(70 \%)$ gave a creamy paste despite a low consumption value $(21 \mathrm{~mL})$, which shows an inability to take up liquid and form an extrudable paste. This was also indicated by the low pellet sphericity $\left(\mathrm{e}_{\mathrm{R}} 0.17\right.$ and 0.15 for mini and conventional pellets).

From Table 3, it can be seen that the mean diameters of the mini pellets were about half the value of the conventional pellets (367 to $585 \mu \mathrm{m}$ compared to 712 to $1206 \mu \mathrm{m}$ ), as expected. Batches B, F, and $\mathrm{H}$ with high CHS2 content and greater liquid consumption gave smaller pellets than batches A, C, and G with high MCC (mean diameters of 367, 411, and $384 \mu \mathrm{m}$ when compared to 532, 516, and $489 \mu \mathrm{m}$ for the mini pellets, and 712, 984, $967 \mu \mathrm{m}$ when compared to 1010, 1013, and $1021 \mu \mathrm{m}$ for the conventional pellets, respectively). The relationship between liquid consumption and pellet diameter (not shown graphically) was linear and inversely proportional $\left(R^{2} 0.689\right.$ for the mini and 0.820 for the conventional pellets), which generally agrees with previous reports [26]. Mini pellets were less spherical ( $e_{R}$ range $0.15-0.44$ compared to $0.16-0.51$, Table 3$)$, and this can be attributed to the more efficient absorption of centrifugal and frictional forces exerted during spheronization by the conventional pellets due to their larger size and mass. 
Table 3. Wetting liquid consumption, paste consistency, pellet size, and pellet shape of the experimental mini and conventional pellet batches.

\begin{tabular}{|c|c|c|c|c|c|c|}
\hline \multirow{2}{*}{$\begin{array}{l}\text { Batch } \\
\text { Code }\end{array}$} & \multirow{2}{*}{$\begin{array}{c}\text { Wetting } \\
\text { Liquid (mL) }\end{array}$} & \multirow{2}{*}{$\begin{array}{c}\text { Paste } \\
\text { Consistency }\end{array}$} & \multicolumn{2}{|c|}{ Mini Pellets } & \multicolumn{2}{|c|}{ Conventional Pellets } \\
\hline & & & $\begin{array}{c}\text { Mean Pellet } \\
\text { Diameter }(\mu \mathrm{m})\end{array}$ & $\begin{array}{c}\text { Shape } \\
\text { Index } e_{R}\end{array}$ & $\begin{array}{c}\text { Mean Pellet } \\
\text { Diameter }(\mu \mathrm{m})\end{array}$ & $\begin{array}{l}\text { Shape } \\
\text { Index } e_{R}\end{array}$ \\
\hline $\mathrm{A}$ & 40.0 & Good & 532 & 0.44 & 1010 & 0.39 \\
\hline $\mathrm{B}$ & 58.0 & Fragile & 367 & 0.27 & 712 & 0.31 \\
\hline $\mathrm{C}$ & 29.0 & Good & 516 & 0.40 & 1013 & 0.41 \\
\hline $\mathrm{D}$ & 21.0 & Creamy & 585 & 0.17 & 1206 & 0.15 \\
\hline $\mathrm{E}$ & 41.0 & Good & 449 & 0.27 & 1001 & 0.51 \\
\hline $\mathrm{F}$ & 52.0 & Good & 411 & 0.32 & 984 & 0.43 \\
\hline G & 42.0 & Plastic & 429 & 0.34 & 1021 & 0.42 \\
\hline $\mathrm{H}$ & 50.0 & Good & 384 & 0.28 & 967 & 0.40 \\
\hline I & 42.0 & Good & 499 & 0.15 & 1002 & 0.16 \\
\hline
\end{tabular}

\subsubsection{Packing, Flowability, and Porosity}

Table 4 presents pycnometric (Ps) and packing densities (bulk $\mathrm{Pb}$ and tap $\mathrm{Pt}$ ), porosity $(\varepsilon \%)$, Carr's compressibility index (CC\%), and flowability. Tap density expresses the extent while CC\% expresses the easiness of packing. The properties of the mini and conventional pellets were correlated linearly ( $\mathrm{R}^{2}$ for: $\mathrm{Ps}=0.856, \mathrm{~Pb}=0.818, \mathrm{Pt}=0.815, \varepsilon \%=0.939$, and flowability of 0.619 ). Mini pellets showed greater Pt values (from 0.67 to 0.87 ) compared to the conventional pellets ( 0.57 to 0.79 ), which is attributed to their smaller size, and, therefore, smaller inter-particle voids less occupied volume. Batches $\mathrm{B}$ and $\mathrm{D}$ with irregular pellet shape gave the lowest $\mathrm{p}_{\mathrm{t}}$ values. The parameter $\mathrm{CC} \%$ presented low values $(<15 \%)$ for both mini and conventional pellets, which indicates good packing ability.

Table 4. Pycnometric densities, packing densities, packing index, porosity, and flowability of the experimental mini and conventional pellets.

\begin{tabular}{|c|c|c|c|c|c|c|c|c|c|c|c|c|}
\hline \multirow{2}{*}{$\begin{array}{l}\text { Batch } \\
\text { Code }\end{array}$} & \multicolumn{6}{|c|}{ Mini Pellets } & \multicolumn{6}{|c|}{ Conventional Pellets } \\
\hline & $\begin{array}{c}\mathrm{Ps} \\
(\mathrm{g} / \mathrm{cc})\end{array}$ & $\begin{array}{c}\mathrm{Pb} \\
(\mathrm{g} / \mathrm{cc})\end{array}$ & $\begin{array}{c}\mathrm{Pt} \\
(\mathrm{g} / \mathrm{cc})\end{array}$ & $\mathrm{CC} \%$ & $\varepsilon \%$ & $\begin{array}{c}\text { Flowability } \\
(\mathrm{g} / \mathrm{s})\end{array}$ & $\begin{array}{c}\text { Ps } \\
(\mathrm{g} / \mathrm{cc})\end{array}$ & $\begin{array}{c}\mathrm{Pb} \\
(\mathrm{g} / \mathrm{cc})\end{array}$ & $\begin{array}{c}\mathrm{Pt} \\
(\mathrm{g} / \mathrm{cc})\end{array}$ & $\mathrm{CC} \%$ & $\varepsilon \%$ & $\begin{array}{c}\text { Flowability } \\
(\mathrm{g} / \mathrm{s})\end{array}$ \\
\hline A & 1.469 & 0.76 & 0.87 & 12.50 & 10.14 & 2.65 & 1.436 & 0.68 & 0.76 & 10.00 & 12.13 & 1.90 \\
\hline B & 1.470 & 0.58 & 0.65 & 10.81 & 6.53 & 2.26 & 1.489 & 0.51 & 0.58 & 11.48 & 5.35 & 1.63 \\
\hline C & 1.556 & 0.72 & 0.80 & 9.52 & 4.29 & 2.37 & 1.594 & 0.65 & 0.70 & 6.94 & 1.97 & 1.74 \\
\hline $\mathrm{D}$ & 1.572 & 0.60 & 0.68 & 12.07 & 0.31 & 1.93 & 1.574 & 0.53 & 0.61 & 13.43 & 0.20 & 1.41 \\
\hline E & 1.476 & 0.71 & 0.82 & 13.16 & 8.19 & 2.32 & 1.516 & 0.66 & 0.75 & 11.59 & 5.75 & 1.95 \\
\hline $\mathrm{F}$ & 1.434 & 0.69 & 0.80 & 13.04 & 11.48 & 2.58 & 1.421 & 0.73 & 0.77 & 4.84 & 12.30 & 2.24 \\
\hline G & 1.460 & 0.79 & 0.86 & 8.47 & 12.45 & 2.81 & 1.433 & 0.72 & 0.79 & 9.72 & 14.10 & 1.99 \\
\hline $\mathrm{H}$ & 1.452 & 0.69 & 0.74 & 6.78 & 8.47 & 2.14 & 1.455 & 0.64 & 0.75 & 14.66 & 8.27 & 1.81 \\
\hline I & 1.514 & 0.61 & 0.67 & 8.20 & 3.89 & 1.78 & 1.526 & 0.51 & 0.57 & 11.94 & 3.08 & 1.40 \\
\hline
\end{tabular}

Ps: pycnometric density. Pb: bulk density. Pt: tap density. CC: Carr's compressibility index. $\varepsilon$ : porosity. Standard deviations for $\mathrm{Ps}<0.015$. $\mathrm{Pb}<0.01$. $\mathrm{Pt}<0.01$. CC $\%<0.03$ and for $\varepsilon \%<0.83(n=3)$.

The porosity ranges of the mini and conventional pellets were similar $(0.31-12.45 \%$ and $0.20-14.10 \%$, respectively). Batches B, E, and $\mathrm{H}$ with high CHS2 and up to $21.25 \% \mathrm{PXC}$ showed low $\varepsilon \%(6.53 \%, 8.19 \%$ and $8.47 \%$ for the mini and $5.35 \%, 5.75$ and $8.27 \%$ for the conventional pellets), which implies a denser structure that is attributed to the binder action of CHS [40]. However, while batches A, F, and G with high MCC showed higher $\varepsilon \%$ values $(10.14 \%, 11.48 \%$, and $12.45 \%$ for mini pellets and $12.13 \%, 12.30 \%$, and $14.10 \%$ for conventional pellets), which is similar to those previously reported for MCC pellets [50]. 
Batches C, D, and I with high PXC showed unusually low porosities $(4.29 \%, 0.31 \%$, and $3.89 \%$ for the mini and $1.97 \%, 0.20 \%$, and $3.08 \%$ for the conventional pellets).

Flowability depends on pellet size, shape, and orifice diameter. The 6-mm orifice was more than six times larger than the diameter of the pellets (means of $452 \mu \mathrm{m}$ and $992 \mu \mathrm{m}$ for mini and conventional, respectively, Table 3) and was selected to avoid blocking [51]. From Table 4, it can be seen that the flowability of the mini pellets was considerably greater than conventional pellet flowability (from 1.76 to $2.82 \mathrm{~g} / \mathrm{min}$ when compared to the 1.35 to $1.99 \mathrm{~g} / \mathrm{min}$ ) despite their lower overall sphericity, which is due to their smaller diameter and easier movement through the orifice.

\subsubsection{Analysis of Mixture Design for the Effect of Composition on Pellet Size, Shape, and Flowability}

Statistically significant model equations with fitting indices derived from the analysis of the experimental design that describe the effects of composition on the pellet diameter, the shape, and flowability for the mini and conventional pellets are presented in Table 5. In all cases there was no lack of fit. Respective contour and trace plots are presented in Figures 3-5. The plots in Figure 3 show that increasing CHS2 decreased the mean pellet diameter for both mini and conventional pellets while PXC caused a diameter increase and MCC had a minimal effect. The model equations were linear ( $R^{2} 0.837$ and 0.742 for mini and conventional pellets respectively). The decrease observed at high CHS2 content is associated with high wetting liquid consumption followed by shrinkage during drying. The increase of the pellet diameter at high PXC is due to the irregular, elongated pellet shape (Figure 1b).

Table 5. Results of regression analysis of the experimental mixture design based on Scheffé quadratic models.

\begin{tabular}{|c|c|c|c|c|c|c|c|c|}
\hline \multirow{2}{*}{ Response } & \multicolumn{4}{|c|}{ Significance of Terms ( $p$-Values) } & \multirow{2}{*}{$\begin{array}{l}\text { Model Equation in Terms of Actual } \\
\text { Components }\end{array}$} & \multirow{2}{*}{$p$-sign. } & \multirow{2}{*}{$\mathbf{R}^{2}$} & \multirow{2}{*}{$\mathbf{R}_{\mathrm{adj}^{2}}{ }^{2}$} \\
\hline & Linear Mixture & $X_{1} X_{2}$ & $x_{1} x_{3}$ & $X_{2} X_{3}$ & & & & \\
\hline $\mathrm{D}_{50} / \mathrm{mini}$ & 0.002 & - & - & - & $+3.45 \mathrm{X}_{1}+4.67 \mathrm{X}_{2}+7.10 \mathrm{X}_{3}$ & 0.002 & 0.837 & 0.742 \\
\hline $\mathrm{D}_{50} /$ conv. & $<0.001$ & 0.004 & 0.058 & 0.006 & $+7.71 \mathrm{X}_{1}+10.80 \mathrm{X}_{2}+13.64 \mathrm{X}_{3}$ & 0.003 & 0.802 & 0.746 \\
\hline $\mathrm{e}_{\mathrm{R}} / \mathrm{mini}$ & 0.021 & - & - & 0.010 & $\begin{array}{l}+2.79 \times 10^{-3} \mathrm{X}_{1}+3.12 \times 10^{-3} \mathrm{X}_{2}-4.82 \\
\quad \times 10^{-3} \mathrm{X}_{3}+1.44 \times 10^{-4} \mathrm{X}_{2} \mathrm{X}_{3}\end{array}$ & 0.010 & 0.832 & 0.748 \\
\hline $\mathrm{e}_{\mathrm{R}} /$ conv. & 0.036 & - & - & 0.120 & $\begin{array}{l}+3.86 \times 10^{-3} X_{1}+4.56 \times 10^{-3} X_{2}-7.37 \\
\times 10^{-4} X_{3}+1.21 \times 10^{-4} X_{2} X_{3}\end{array}$ & 0.042 & 0.721 & 0.581 \\
\hline Flowability/mini & 0.015 & 0.273 & 0.163 & - & $\begin{array}{l}+0.023 \mathrm{X}_{1}+0.027 \mathrm{X}_{2}+0.023 \mathrm{X}_{3}+1.826 \\
\quad \times 10^{-4} \mathrm{X}_{1} \mathrm{X}_{2}-2.815 \times 10^{-4} \mathrm{X}_{1} \mathrm{X}_{3}\end{array}$ & 0.033 & 0.838 & 0.708 \\
\hline Flowability/conv. & $<0.001$ & 0.001 & - & - & $\begin{array}{c}+0.013 \mathrm{X}_{1}+0.019 \mathrm{X}_{2}+0.013 \mathrm{X}_{3}+3.518 \\
\times 10^{-4} \mathrm{X}_{1} \mathrm{X}_{2}\end{array}$ & $<0.001$ & 0.956 & 0.934 \\
\hline $\mathrm{DE} \% / \mathrm{pH} 1.2 / \mathrm{mini}$ & 0.298 & - & 0.012 & - & $\begin{array}{c}+0.22 \mathrm{X}_{1}+0.72 \mathrm{X}_{2}+0.26 \mathrm{X}_{3}+ \\
0.03 \mathrm{X}_{1} \mathrm{X}_{3}\end{array}$ & 0.042 & 0.722 & 0.582 \\
\hline $\mathrm{DE} \% / \mathrm{pH} 1.2 /$ conv. & 0.004 & 0.172 & 0.001 & - & $\begin{array}{c}+0.07 X_{1}+0.72 X_{2}+0.44 X_{3}+5.61 \times 10 \\
-3 X_{1} X_{2}+0.02 X_{1} X_{3}\end{array}$ & 0.002 & 0.945 & 0.902 \\
\hline $\mathrm{DE} \% / \mathrm{pH} 5.6 / \mathrm{mini}$ & $<0.001$ & 0.084 & 0.015 & 0.001 & $\begin{array}{c}+0.70 \mathrm{X}_{1}+0.47 \mathrm{X}_{2}+0.57 \mathrm{X}_{3}+ \\
5.70 \times 10^{-3} \mathrm{X}_{1} \mathrm{X}_{2}-0.01 \mathrm{X}_{1} \mathrm{X}_{3}- \\
0.02 \mathrm{X}_{2} \mathrm{X}_{3}\end{array}$ & 0.001 & 0.983 & 0.962 \\
\hline $\mathrm{DE} \% / \mathrm{pH} 5.6 /$ conv. & 0.042 & - & - & 0.029 & $+0.16 X_{1}+0.25 X_{2}+0.71 X_{3}-0.01 X_{2} X_{3}$ & 0.026 & 0.764 & 0.646 \\
\hline $\mathrm{td} / \mathrm{pH} 1.2 / \mathrm{mini}$ & 0.543 & 0.072 & 0.009 & - & $\begin{array}{c}1.44 \mathrm{X}_{1}+0.702 \mathrm{X}_{2}+1.188 \mathrm{X}_{3}- \\
0.025 \mathrm{X}_{1} \mathrm{X}_{2}-0.054 \mathrm{X}_{1} \mathrm{X}_{3}\end{array}$ & 0.039 & 0.825 & 0.685 \\
\hline $\mathrm{td} / \mathrm{pH} 1.2 / \mathrm{conv}$ & 0.069 & - & 0.042 & - & $\begin{array}{c}1.079 \mathrm{X}_{1}+0.439 \mathrm{X}_{2}+0.676 \mathrm{X}_{3}- \\
0.030 \mathrm{X}_{1} \mathrm{X}_{3}\end{array}$ & 0.044 & 0.717 & 0.576 \\
\hline $\mathrm{td} / \mathrm{pH} 5.6 / \mathrm{mini}$ & 0.027 & - & 0.054 & 0.103 & $\begin{array}{c}0.234 \mathrm{X}_{1}+1.108 \mathrm{X}_{2}+0.478 \mathrm{X}_{3}- \\
0.036 \mathrm{X}_{1} \mathrm{X}_{3}+0.024 \mathrm{X}_{2} \mathrm{X}_{3}\end{array}$ & 0.035 & 0.833 & 0.699 \\
\hline $\mathrm{td} / \mathrm{pH} 5.6 /$ conv. & $<0.001$ & - & $<0.001$ & $<0.001$ & $\begin{array}{c}0.084 \mathrm{X}_{1}+0.6118 \mathrm{X}_{2}-0.171 \mathrm{X}_{3}+ \\
0.058 \mathrm{X}_{1} \mathrm{X}_{3}+0.044 \mathrm{X}_{2} \mathrm{X}_{3}\end{array}$ & $<0.001$ & 0.979 & 0.963 \\
\hline$\%$ Released 2h/pH5.6 & $<0.001$ & & 0.016 & 0.002 & $\begin{array}{c}0.817 X_{1}+0.513 X_{2}+0.570 X_{3}- \\
0.01 X_{1} X_{3}-0.02 X_{2} X_{3}\end{array}$ & $<0.001$ & 0.964 & 0.935 \\
\hline \%Released 8h/pH5.6 & 0.002 & 0.029 & - & 0.002 & $\begin{array}{c}0.737 X_{1}+0.790 X_{2}+0.747 X_{3}+ \\
0.013 X_{1} X_{2}-0.025 X_{2} X_{3}\end{array}$ & 0.002 & 0.953 & 0.916 \\
\hline
\end{tabular}

$\mathrm{X}_{1}$ : Chitosan. $\mathrm{X}_{2}$ : Microcrystalline cellulose. $\mathrm{X}_{3}$ : Drug. $\mathrm{D}_{50}$ : median pellet diameter. $\mathrm{e}_{\mathrm{R}}$ : shape coefficient. $\mathrm{DE} \%$ : dissolution efficiency. td: parameter in the Weibull equation. 


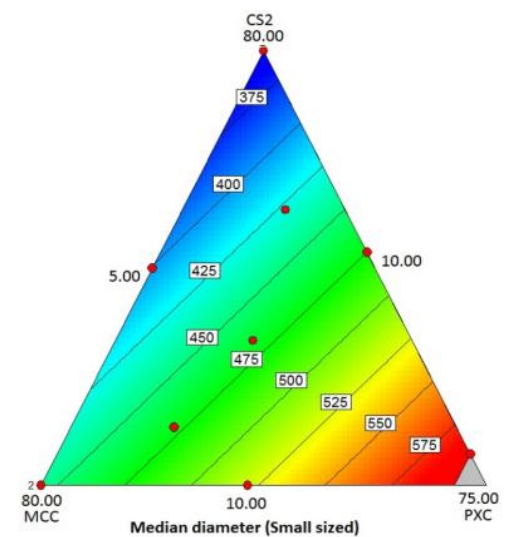

(a)
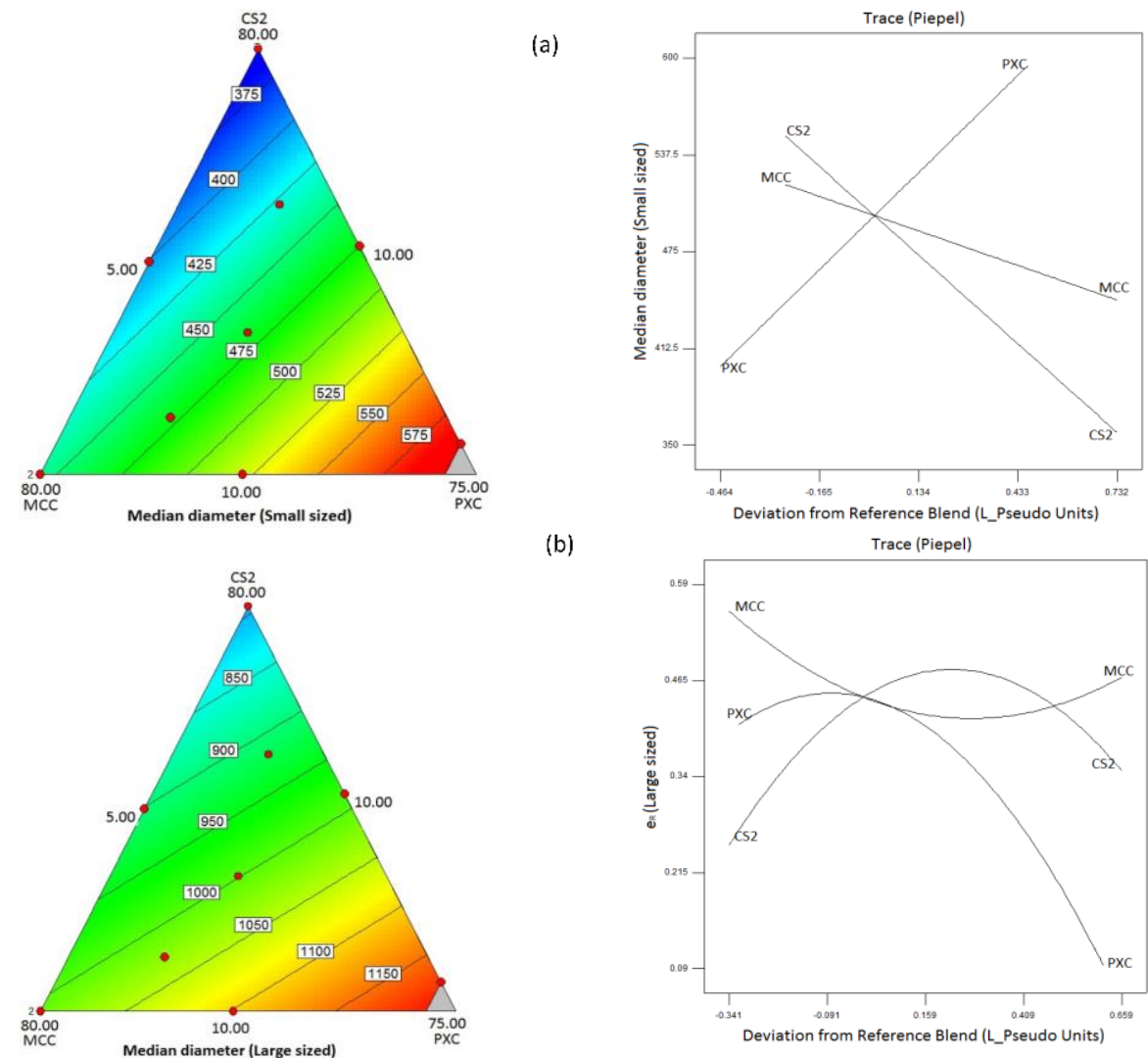

(b)

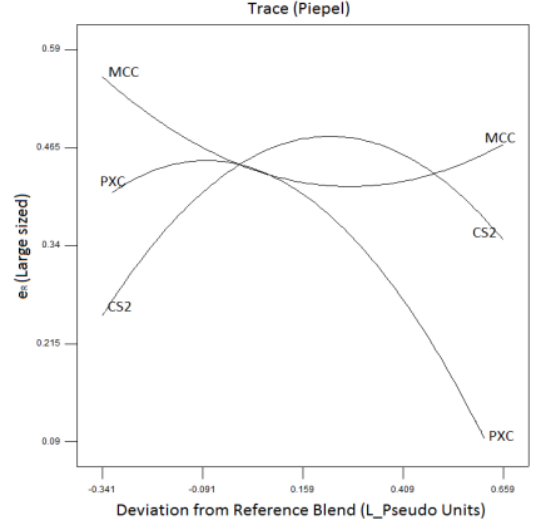

Figure 3. Contour and trace plots of mean pellet diameters for (a) mini and (b) conventional pellets.

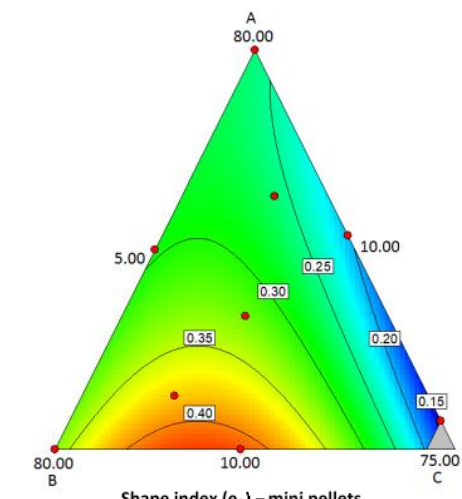

(a)
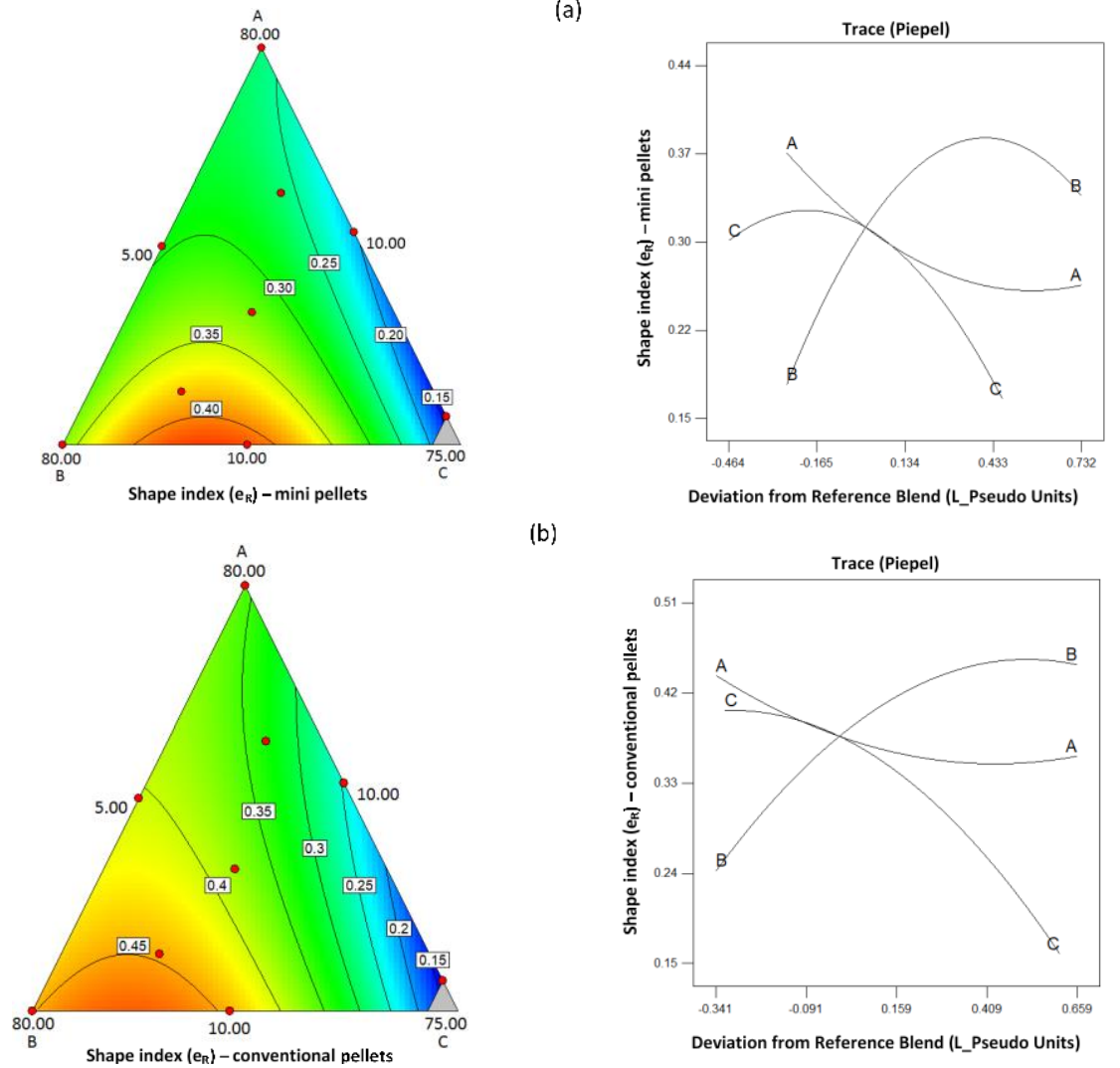

(b)

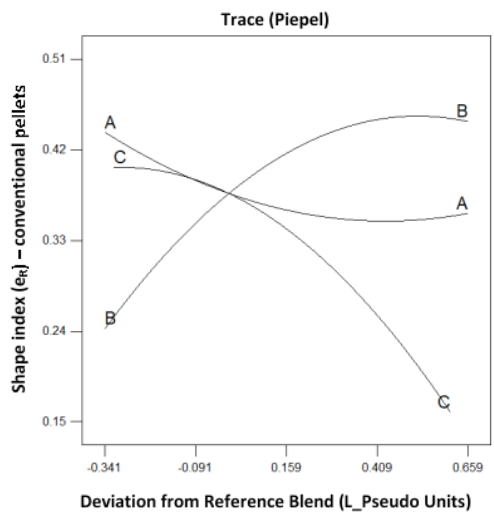

Figure 4. Contour and trace plots of the shape index $e_{R}$ for (a) mini and (b) conventional pellets. 


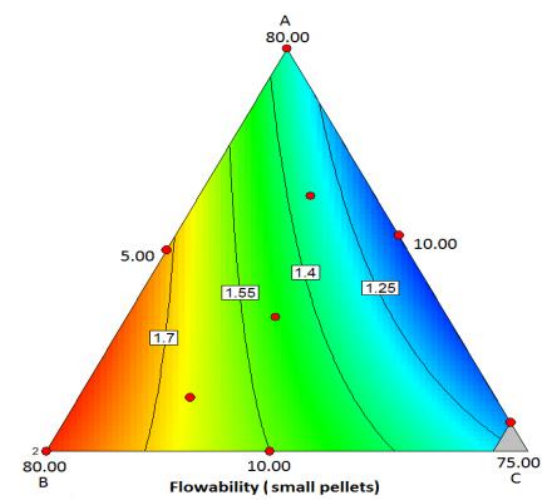

(a)

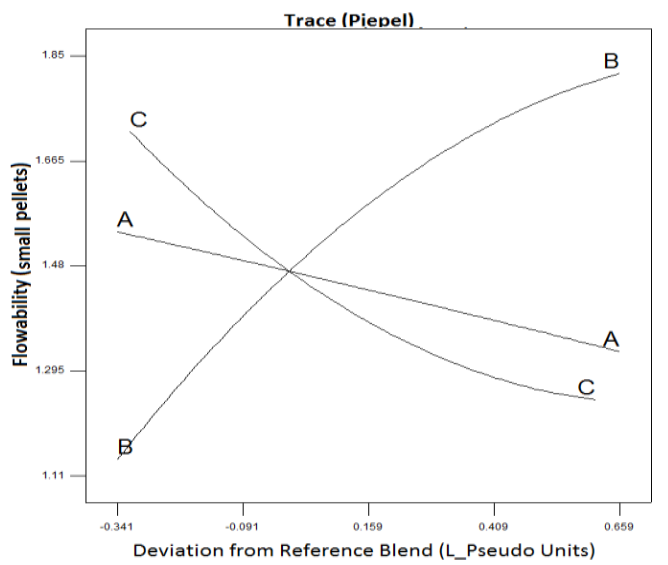

(b)
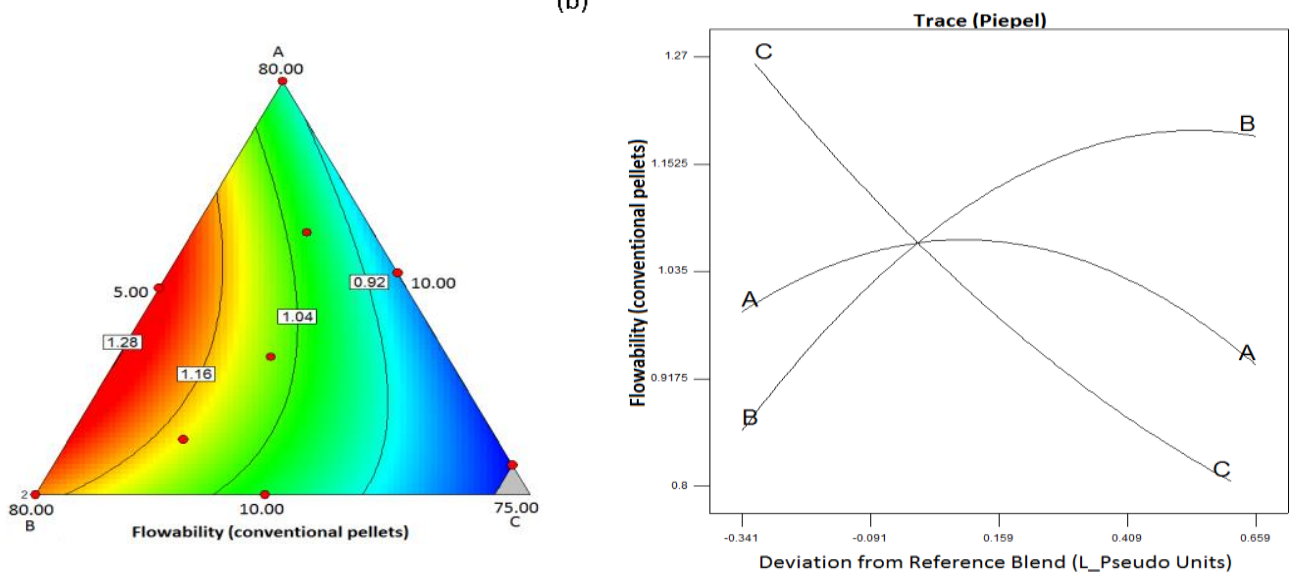

Figure 5. Contour and trace plots of flowability for (a) mini and (b) conventional pellets.

Considering the pellet shape, from the trace plots in Figure 4, it can be seen that sphericity was adversely affected by PXC for both mini and conventional pellets. It was positively affected by MCC while CHS2 had a small effect. The increased irregularity at high drug content is due to the lack of sufficient excipients resulting in a creamy paste even at low volumes of added liquid (batch D, Table 3). The regression model for both mini and conventional pellets was reduced quadratic $\left(R^{2} 0.885\right.$ and 0.901) with an interaction of the effects of MCC and PXC, i.e., at low MCC levels, the effect of drug content was small but strongly negative at high MCC (Figure 4b). Furthermore, from Figure 5, it can be seen that MCC had a positive effect, whereas the drug had a negative effect on flowability, which can be explained by their respective effects on sphericity (Figure 4). The model describing the effects of composition on flowability was reduced quadratic for both mini and conventional pellets $\left(R^{2} 0.838\right.$ and 0.956 ), which was indicated by curvilinear plots.

\subsection{Physicochemical Evaluation}

\subsubsection{Raman Spectroscopy}

Raman spectra provide information regarding interactions of drugs with excipients. In Figure 6, the spectra of chitosan (CHS2), microcrystalline cellulose (MCC), piroxicam (PXC), and batches C, 1 with $37.5 \%$ drug and low or high CHS/MCC ratio (10/47.5 and 47.5/10), respectively, are presented. The CHS2 spectrum showed two small peaks at $119 \mathrm{~cm}^{-1}$ and $583 \mathrm{~cm}^{-1}$. The MCC spectrum showed one small double peak at $1196 / 1120 \mathrm{~cm}^{-1}$. The PXC spectrum showed a large fingerprint region in the range of 1090 to $1661 \mathrm{~cm}^{-1}$ (enclosed by vertical dotted lines), which is due to the complex patterns of $\mathrm{C}-\mathrm{C}, \mathrm{C}-\mathrm{N}$, and aromatic ring vibrations [52]. The drug peaks at 1543 and $1570 \mathrm{~cm}^{-1}$ are due to ring stretching and $\mathrm{C}=\mathrm{C}$ symmetric stitching vibrations, respectively (indicated by arrows), are present in 
both C, I spectra and are characteristic of form II [53]. The spectra of both C and I showed the same peaks in the fingerprint region as the drug spectrum, which indicates no polymorphic transformation or interaction due to processing. Furthermore, peaks at 1007 and $1401 \mathrm{~cm}^{-1}$ that are characteristic of the PXC monohydrate $[35,53]$ are not seen in the spectra of drug or pellet batches, which indicates an absence of the monohydrate drug.

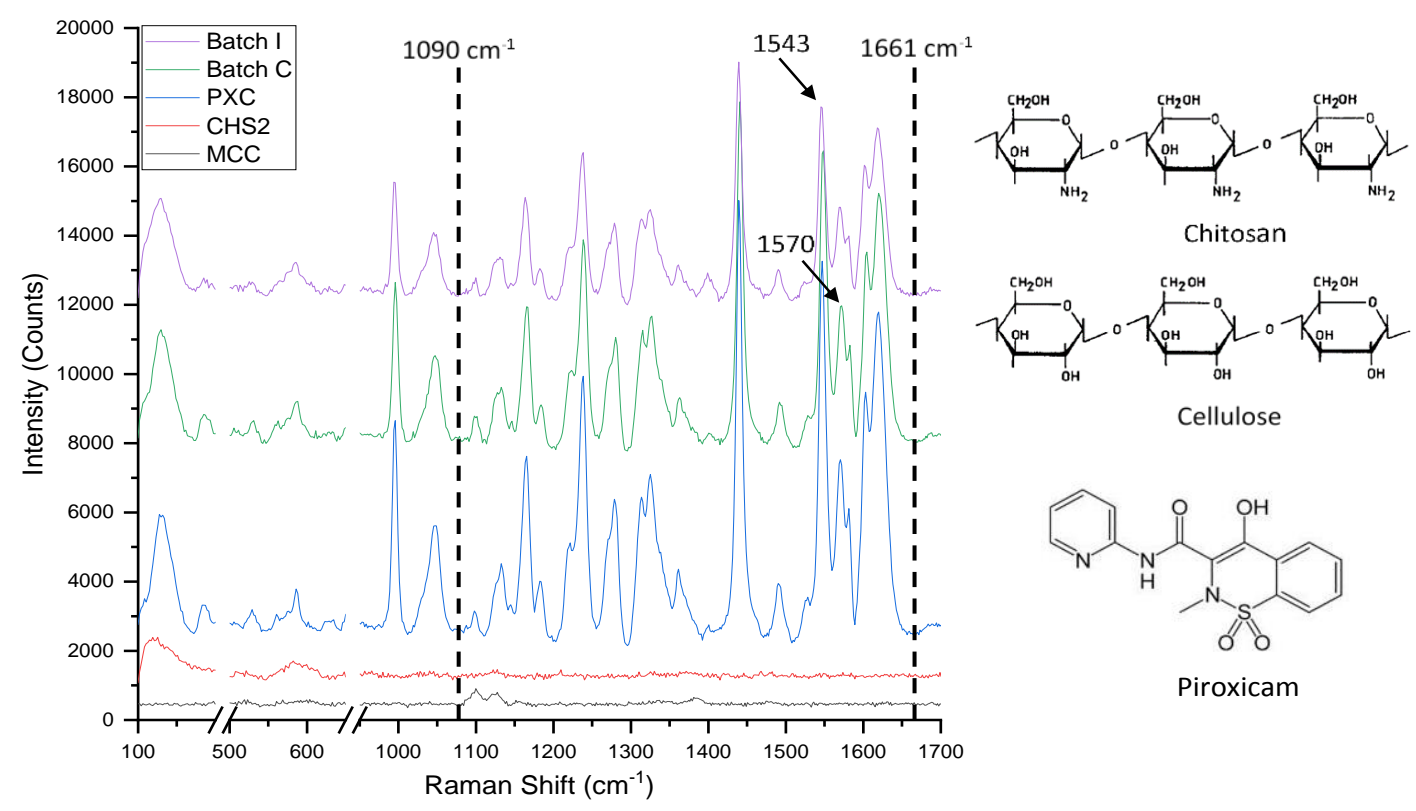

Figure 6. Chemical structures and Raman spectra of microcrystalline cellulose (MCC), chitosan (CHS2), unprocessed drug (PXC), and experimental batch I (CHS2 47.5\%, MCCI 10\%, PXC 37.5\%).

\subsubsection{Powder X-ray Diffraction (PXRD)}

PXRD patterns provide detailed information about the crystallinity of the drug in the pellet batches. Figure 7 presents the patterns of CHS2, MCC, and PXC powders, pellet batches B and G with low $5 \%$ drug and high ( $80 \%$ ) or low (10\%) CHS2, and batches $\mathrm{H}$ and A with higher $21.25 \%$ drug and high $(54.37 \%)$ or low CHS2 $(19.38 \%)$. The CHS2 pattern showed one small reflection at $10.9^{\circ} 2 \theta$ and one strong reflection at $20.0^{\circ} 2 \theta$, whereas the MCC pattern showed three reflections with one broad between $15^{\circ}$ and $16.5^{\circ} 2 \theta$, one strong at $22.3^{\circ} 2 \theta$, and one small at $34.2^{\circ} 2 \theta$.

The PXC pattern showed sharp reflections at $9.1^{\circ}$ and $10.2^{\circ} 2 \theta$, four consecutive reflections between $15^{\circ}$ and $17^{\circ} 2-\theta$, and strong, sharp, reflections at $15.9^{\circ}, 26.1^{\circ}$, and $27.1^{\circ} 2 \theta$. The strong reflection at $9.1^{\circ}$ and the consecutive reflections at $26.1^{\circ} / 27.1^{\circ} 2 \theta$ confirm the presence of the anhydrous form, which is in agreement with the Raman spectroscopy results. Additionally, from the PXRD pattern of PXC and using the database of the International Center of Diffraction Data (ICDD 2003) [54], it can be inferred that the form-II (44-1839 ICDD card) of the piroxicam structure is the major phase, while the form-I (40-1982 ICDD card) is identified as the minor phase. More specifically, using the mass absorption coefficient, the density, and the specific reflections of each form, it is estimated that form-II constitutes $69 \% w / w$ of the drug, while form-I is $31 \% w / w$. From the patterns of the pellets shown in Figure 7 , it appears that the drug reflections at $9.1^{\circ} / 10.2^{\circ}$ and $26.1^{\circ} / 27.1^{\circ} 2 \theta$ are still discernible in the PXRDs of batches $G$ and B (though small due to the low drug content), and are clearly seen in the PXRDs of batches $\mathrm{A}$ and $\mathrm{H}$ with higher drug content, which indicates the predominantly crystalline state of the drug. 


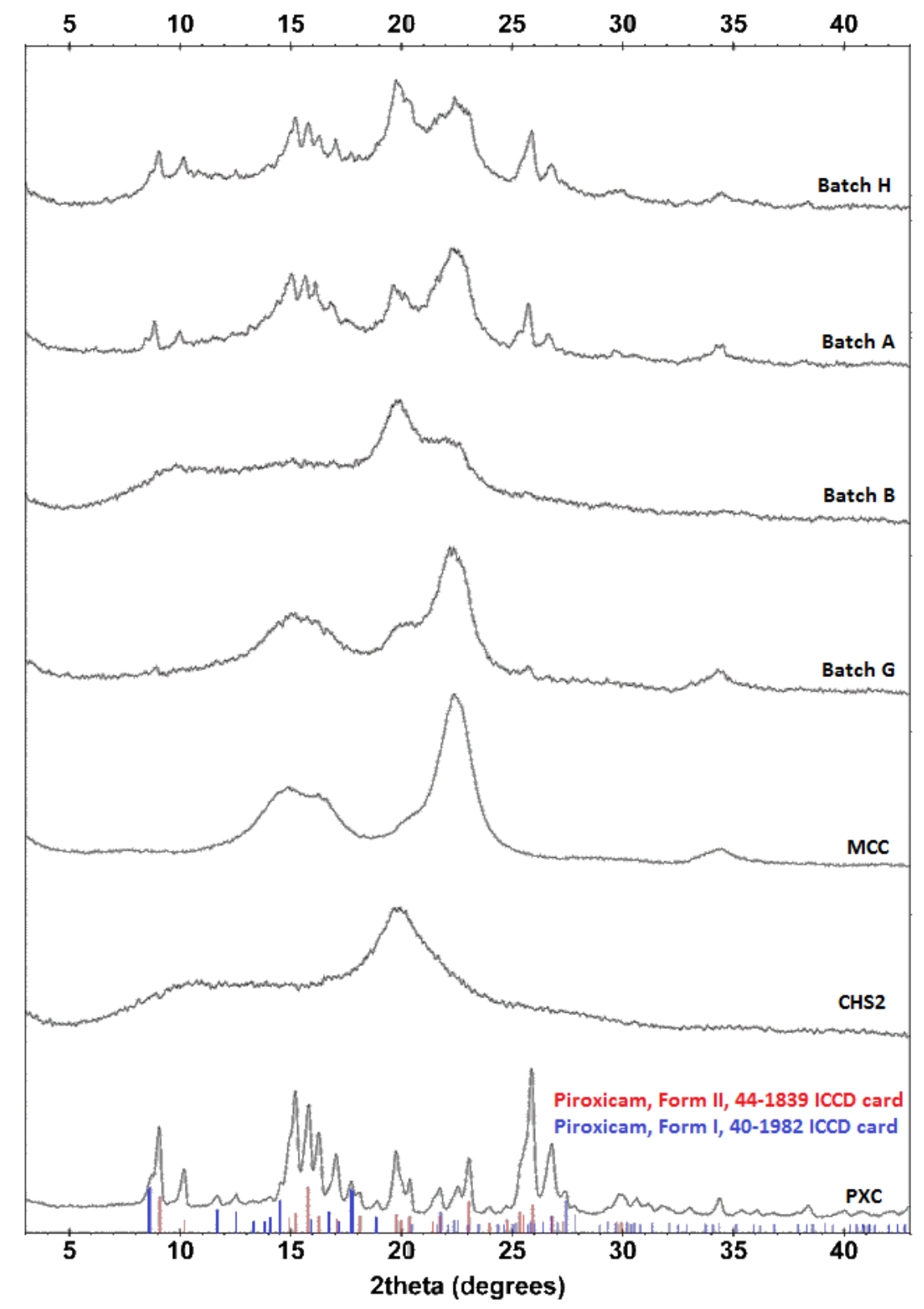

Figure 7. PXRDs for unprocessed materials and batches B and G with $5 \%$ drug content, and batches A and $\mathrm{H}$ with $21.25 \%$ drug content.

Crystallinity indices of the drug for the experimental pellet batches with $5 \%(B, G), 21.25 \%(A, H)$, and $37.5 \%$ drug $(\mathrm{C}, \mathrm{I})$, and their corresponding physical mixtures are presented in Table 6 . In all cases, there is a loss of percentage in crystallinity due to processing, which is greater for the low drug batches B and G (21.14-22.57\% compared to $2.51-3.87 \%$ for $\mathrm{A}$ and $\mathrm{H}$, and $2.54-3.98 \%$ for $\mathrm{C}$ and I). It is documented that CHS2 is able to amorphize drugs processed by wet granulation [25]. (PVP is also an amorphizer but, because it is included with a low content of $5 \%$, its contribution is negligible [55]). This effect should result from the dissolution of some drug content during wetting/extrusion, which is subsequently converted to an amorphized form after drying. Since the effect of CHS on solubility at a pH of 5.6 is independent of CHS content (Figure 1b), the amount of amorphized crystalline drug should not differ between batches, which explains the greater percentage of crystallinity loss observed in batches B and G with low drug content. Comparing batches with the same PXC content, it can be seen that the differences in crystallinity loss are small, regardless of the CHS/MCC ratio. 
Table 6. Crystallinity index (CI\%) of the drug in the experimental pellet batches and the corresponding physical mixtures (PM). (Intensity of the drug at $25.82 \theta$ degrees 2132.55 a.u.).

\begin{tabular}{cccc}
\hline Batch Code/Drug\% & CI\% of Drug in PM & CI\% of Drug in Pellet & Crystallinity Loss (\%) \\
\hline $\mathrm{B} / 5$ & $24.73 \pm 0.31$ & $19.15 \pm 0.05$ & $22.56 \pm 0.09$ \\
\hline $\mathrm{G} / 5$ & $21.62 \pm 0.02$ & $17.05 \pm 0.18$ & $21.14 \pm 0.17$ \\
\hline $\mathrm{A} / 21.25$ & $35.96 \pm 0.21$ & $34.57 \pm 0.15$ & $3.87 \pm 0.42$ \\
\hline $\mathrm{H} / 21.25$ & $33.84 \pm 0.03$ & $32.99 \pm 0.04$ & $2.51 \pm 0.48$ \\
\hline $\mathrm{C} / 37.5$ & $55.29 \pm 0.18$ & $53.09 \pm 0.16$ & $3.98 \pm 0.26$ \\
\hline $\mathrm{I} / 37.5$ & $58.21 \pm 0.19$ & $56.73 \pm 0.21$ & $2.54 \pm 0.34$ \\
\hline
\end{tabular}

\subsection{In-Vitro Release}

In Figure 8, release profiles of mini and conventional pellets at two $\mathrm{pH}$ media (pH 1.2 and 5.6) are presented together with data from MCC/PXC pellets without chitosan for comparison purposes. Although the stay of the drug in the stomach delivered by conventional formulations is usually less than $120 \mathrm{~min}$., this time may increase considerably for the present pellet formulations due to the muco-adhesive properties of chitosan [56]. For this reason, release studies of up to 500 min were conducted since the release exceeded this period for some pellet batches. Representative images of pellets before and after dissolution at $\mathrm{pH} 1.2$ are shown in Figure 9 for batches A and C. Figure 10 presents images of all experimental batches before and after dissolution in deionized water ( $\mathrm{pH}$ 5.6). The dissolution efficiency (DE\%) and similarity factors (f2) comparing drug release from mini and conventional sized pellets at pH 1.2 and pH 5.6 are given in Table 7.
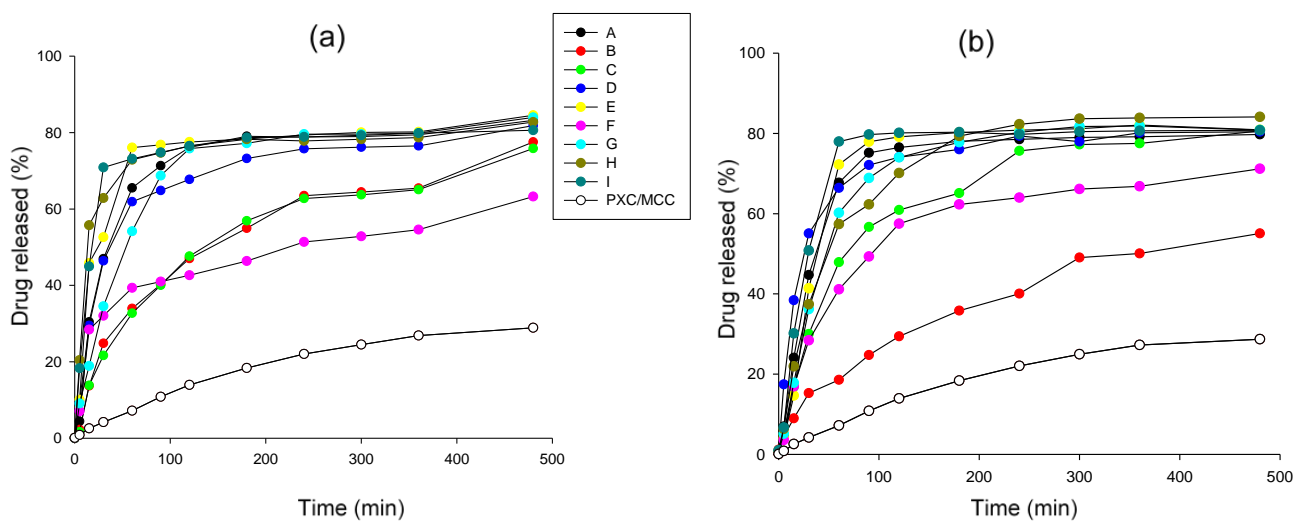

(c)

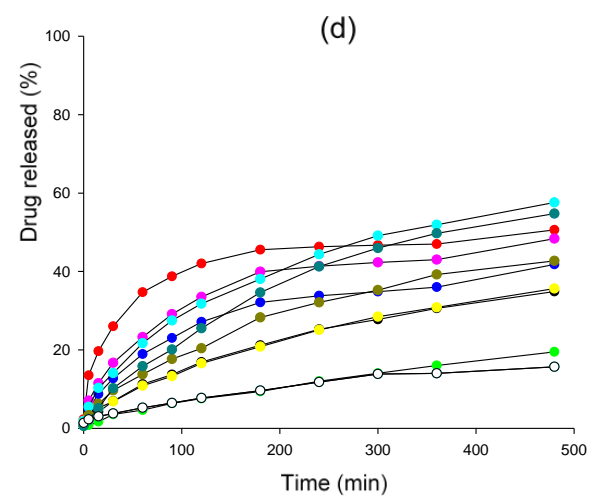

Figure 8. Release profiles of: (a) mini pellets at $\mathrm{pH} 1.2$, (b) conventional pellets at $\mathrm{pH} 1.2$, (c) mini pellets at 5.6, and (d) conventional pellets at $\mathrm{pH}$ 5.6. Release of drug from pellets prepared without chitosan (PXC/MCC) is also shown for comparison purposes. 
Batch A
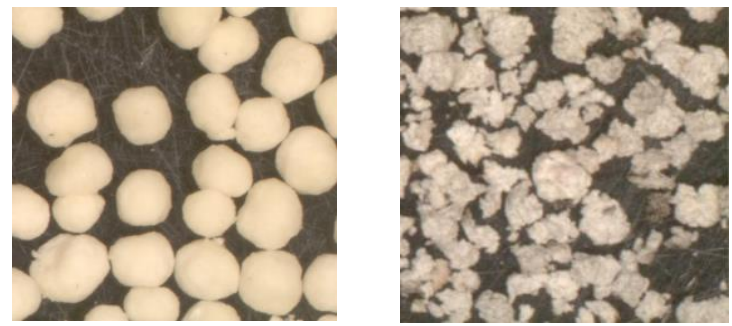

Batch C
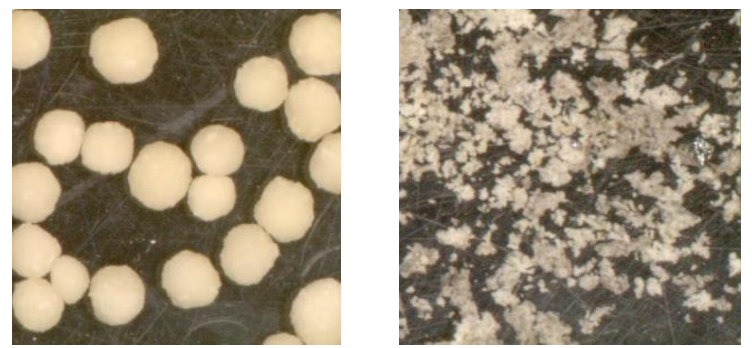

Figure 9. Images of pellets from batches A and C before (left) and after (right) the dissolution test at pH 1.2.

(a)

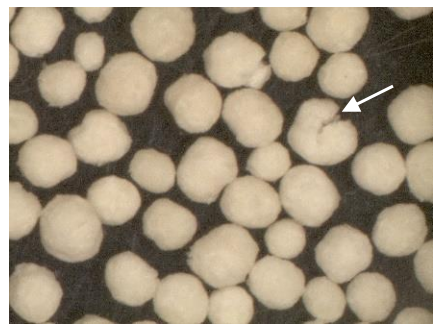

(d)

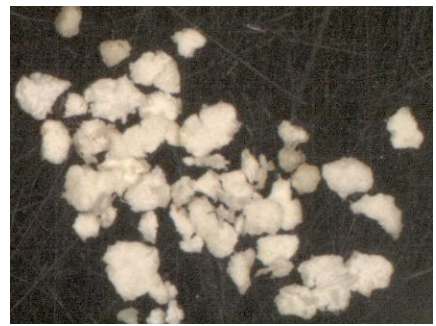

(g)

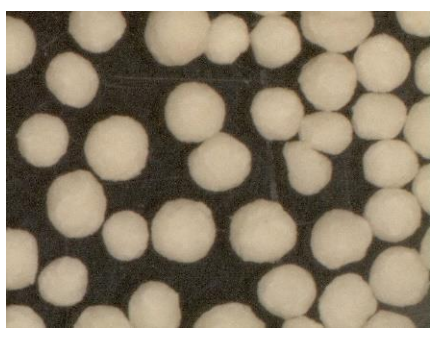

(b)

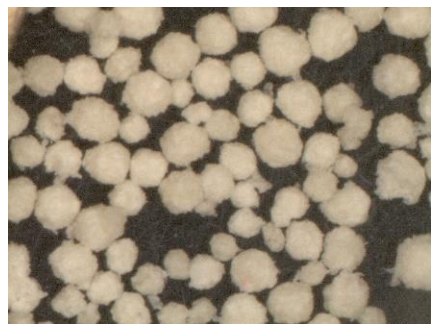

(e)

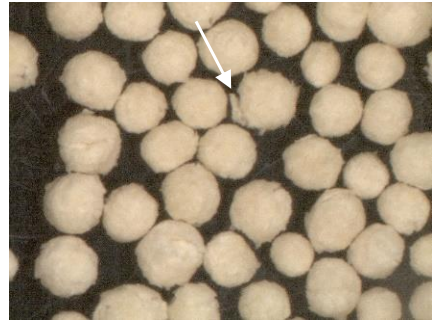

(h)

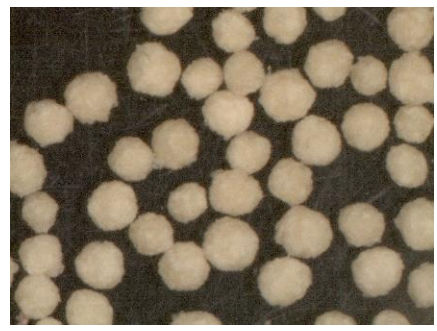

(c)

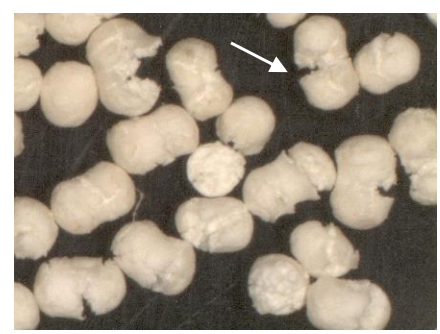

(f)

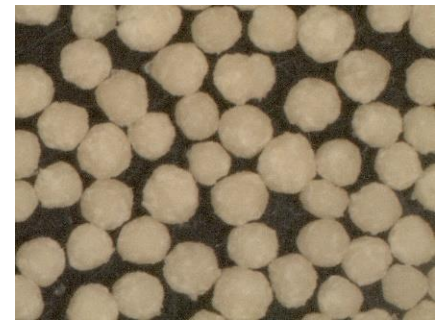

(i)

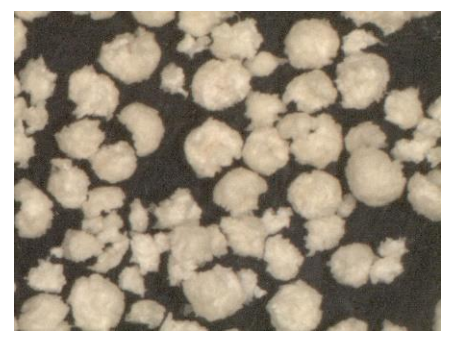

Figure 10. Images of pellets from all experimental batches (a-i) (Table 1) collected and dried after dissolution testing at $\mathrm{pH} 5.6$ (Arrows indicate areas of disruption). 
Table 7. Dissolution efficiency (DE\%) (mean $\pm \mathrm{SD}, n=3$ ) and similarity factors (f2) comparing drug release from mini and conventional pellets at $\mathrm{pH} 1.2$ and 5.6.

\begin{tabular}{ccccccc}
\hline \multirow{2}{*}{ Batch Code } & \multicolumn{2}{c}{ DE\% for Mini Pellets at: } & \multicolumn{2}{c}{$\begin{array}{c}\text { DE\% for Conventional } \\
\text { Pellets at: }\end{array}$} & \multicolumn{2}{c}{$\begin{array}{c}\text { Similarity Factor (f2) } \\
\text { Comparing Mini and } \\
\text { Conventional Pellets at: }\end{array}$} \\
\cline { 2 - 7 } & $\mathbf{p H ~ 1 . 2}$ & $\mathbf{p H ~ 5 . 6}$ & $\mathbf{p H ~ 1 . 2}$ & $\mathbf{p H ~ 5 . 6}$ & $\mathbf{p H ~ 1 . 2}$ & pH 5.6 \\
\hline A & $67.56 \pm 0.74$ & $28.26 \pm 0.17$ & $69.48 \pm 1.12$ & $19.73 \pm 0.39$ & 77.90 & 51.93 \\
\hline B & $38.85 \pm 1.86$ & $61.43 \pm 1.52$ & $30.44 \pm 2.56$ & $17.75 \pm 1.89$ & 44.44 & 37.00 \\
\hline C & $44.87 \pm 1.42$ & $15.09 \pm 1.05$ & $58.53 \pm 2.74$ & $9.40 \pm 1.14$ & 50.83 & 61.14 \\
\hline D & $64.46 \pm 0.23$ & $29.85 \pm 0.68$ & $70.16 \pm 1.54$ & $43.24 \pm 0.27$ & 62.07 & 53.94 \\
\hline E & $70.70 \pm 0.41$ & $30.73 \pm 0.37$ & $71.01 \pm 1.32$ & $19.73 \pm 0.84$ & 49.30 & 47.75 \\
\hline F & $43.78 \pm 1.36$ & $60.23 \pm 1.89$ & $52.44 \pm 1.95$ & $13.45 \pm 1.07$ & 52.48 & 31.74 \\
\hline G & $60.64 \pm 0.65$ & $40.10 \pm 0.41$ & $66.85 \pm 1.10$ & $10.76 \pm 0.31$ & 69.82 & 45.43 \\
\hline H & $70.41 \pm 0.59$ & $45.46 \pm 1.24$ & $67.03 \pm 0.89$ & $25.26 \pm 0.27$ & 41.26 & 35.77 \\
\hline I & $71.84 \pm 0.61$ & $33.25 \pm 1.18$ & $73.05 \pm 1.27$ & $31.49 \pm 0.02$ & 53.02 & 65.12 \\
\hline
\end{tabular}

Comparing Figure $8 \mathrm{a}$ with Figure $8 \mathrm{c}-\mathrm{d}$, it can be seen that release at $\mathrm{pH} 1.2$ is generally faster than at $\mathrm{pH}$ 5.6. This can be explained partly by the greater 'apparent' solubility of the drug at $\mathrm{pH} 1.2$ than at pH 5.6 in the presence of CHS2 (0.238 compared to $0.157 \mathrm{mg} / \mathrm{mL}$, Figure 2), but mainly due to the different state of the pellet matrix in the two $\mathrm{pH}$ media. Since CHS dissolves in $\mathrm{pH} 1.2$ but not in $\mathrm{pH}$ 5.6, the pellet matrix dissolves and erodes during dissolution testing, in parallel to diffusion (Figure 9). However, in deionized water, erosion occurs to a much lower extent (Figure 10). Additionally, from Figure $8 \mathrm{a}-\mathrm{d}$, it can be seen that the pellet batch prepared with MCC/PXC only (black line open circles) showed much lower release, which underlines the importance of chitosan as already reported for other drugs [57].

From Figure 8a,b, it can be seen that, in six of nine cases, drug release at $\mathrm{pH} 1.2$ completes within $3 \mathrm{~h}$. Faster release was obtained from batches $\mathrm{H}$ and I with high $\mathrm{CHS} /$ medium or high drug (Table 1) (60-70\% within $30 \mathrm{~min}$ from mini and about $50 \%$ from conventional pellets. Together with batch $\mathrm{E}$, these batches also gave higher DE\% values for both mini and conventional pellets (Table 7). Batches $\mathrm{B}$ and F with high CHS/low PXC and batch C with low CHS/high PXC, respectively, showed the lowest DE\% (Table 7) and extended release. However, since erosion was involved (Figure 9), the extended release observed was highly dependent on composition and difficult to control. For example, the curves of batches B and C are located closer together than those of batches A and C (Figure 8a,b), despite the greater similarity in compositions of the latter two (Table 1).

The plateaus in the curves in the $8 \mathrm{~h}$ dissolution-testing period corresponded to less than $100 \%$ release, which may be partly ascribed to changes in solubility due to transformation into a hydrate form of lower solubility during dissolution [35], but also to the continued slow release after $8 \mathrm{~h}$. In fact, measurements over a longer dissolution time showed that drug released (\%) was still increasing and reaching above $85 \%$ after $24 \mathrm{~h}$ for both mini and conventional pellets, with the exception of conventional pellet batch B (70\% release). For the purpose of this study, the end of the test period was considered to be $8 \mathrm{~h}$. The $\mathrm{DE} \%$ values for the mini and conventional pellets were linearly correlated $\left(\mathrm{R}^{2}=0.880\right)$ and differences between their release profiles were small. Only batches B and $\mathrm{H}$ had similarity factors f2 $<50$. These contained high CHS ( $80 \%$ and $54.37 \%$, Table 1$)$. Therefore, gel formation, diffusional release, and pellet size had higher significance than for other batches [30].

From Figure $8 c, d$, it can be seen that, at $\mathrm{pH} 5.6$, the profiles of the mini pellets differed greatly from the conventional pellet profiles with the latter displaying much slower release $(<50 \%$ after $8 \mathrm{~h})$, which precludes practical use. From the values of the similarity factors $\mathrm{f} 2$ in Table 7 , it appears that only batches A, C, D, and I showed similarity between mini and conventional pellets ( $f 2>50$ ). These batches 
all had high PXC content (37.5\% or 70\%) and exhibited erosion after dissolution testing (Figure 10), which alters the diffusional release. Figure $8 \mathrm{c}$ shows that the release curves of the mini pellets fall into three groups where: one group has a faster release (over $80 \%$ in $8 \mathrm{~h}$ ) and comprises batches $\mathrm{B}$ and $\mathrm{F}$, with high CSH2/PXC ratios of 16.0 and 9.0, respectively; a second group comprises batches $\mathrm{G}$ and $\mathrm{H}$ with CSH2/PXC ratios of 2.0 and 2.5 and releases $70-80 \%$ after $8 \mathrm{~h}$; a the third group comprises batches A, D, E, and I with CSH2/PXC ratios of $0.91,0.21,1.25$, and 1.27, respectively, showing low release between $50 \%$ and $60 \%$. Batch $\mathrm{C}$ that had a CSH2/PXC ratio of 0.27 , showed poor release. The latter five batches with reduced or poor release exhibited erosion and loss of matrix integrity after testing (Figure 10), which altered the beneficial release effect. On the other hand, batches B, F, G, and $\mathrm{H}$ of mini pellets, which did not disintegrate, showed good extended release over $8 \mathrm{~h}$. Of these, batches B, F, and G also gave extended release at $\mathrm{pH} 1.2$ and, therefore, appear to be promising extended-release formulations.

From the above, it appears that, when the $\mathrm{CSH} / \mathrm{PXC}$ ratio was $\geq 2$, the pellet matrix retains the characteristics of the chitosan network, which results in extended and complete release after $8 \mathrm{~h}$.

Table 5 shows statistically significant model equations derived from regression analysis of the experimental design describing the effect of composition on the dissolution efficiency (DE\%) at $\mathrm{pH} 1.2$ for mini and conventional pellets. The respective contour and trace plots are presented in Figure 11. From the contour plots, it appears that, at $\mathrm{pH} 1.2$, greater $\mathrm{DE} \%$ is obtained for intermediate levels of the three components, and the trace plots show clearly that CHS exerts the greatest effect. Statistically significant model equations for the effect of composition on $\mathrm{DE} \%$ at $\mathrm{pH} 5.6$ for mini and conventional pellets are also given in Table 5, with their respective contour and trace plots in Figure 12. It can be seen that, contrary to the effect of CHS2 at $\mathrm{pH} 1.2$, at $\mathrm{pH} 5.6$, greater $\mathrm{DE} \%$ is obtained for the mini pellets at high CHS and low drug content and that these two components had the greatest effect (Figure 12). The conventional pellets showed very low DE\% (values $9.40 \%$ to $31.49 \%$, Table 7), which indicates poor release. The trace plots in Figure 12 show that for the conventional pellets at pH 5.6 the drug component had the greater effect on the release.

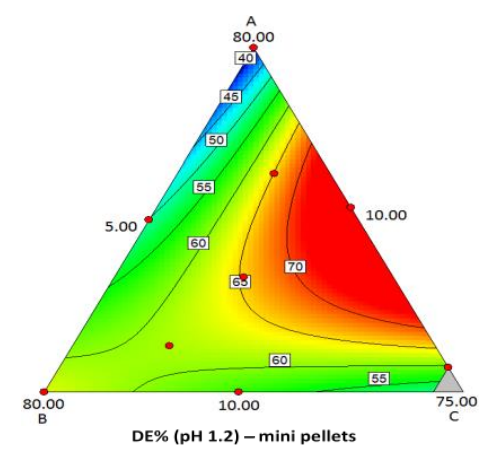

(a)
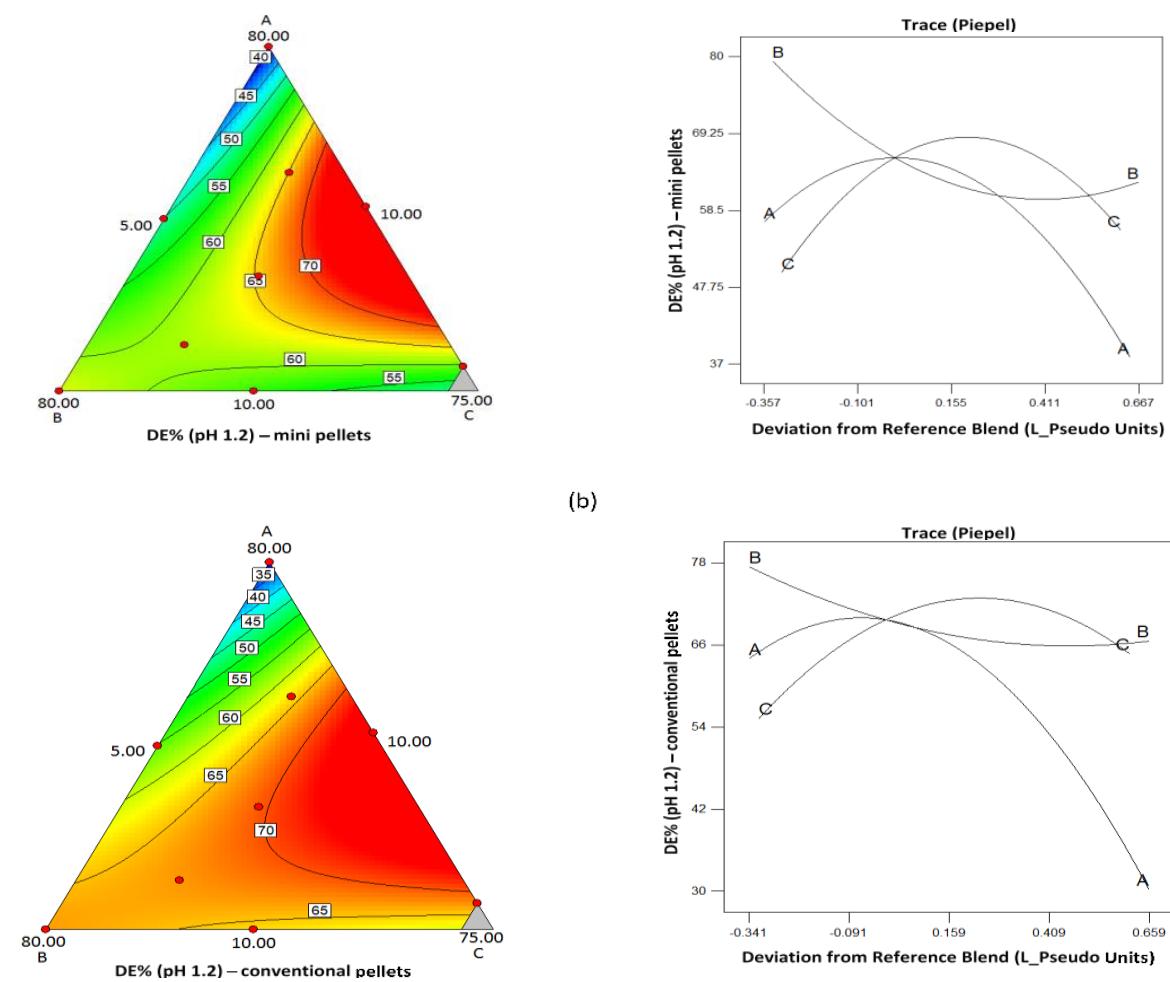

(b)

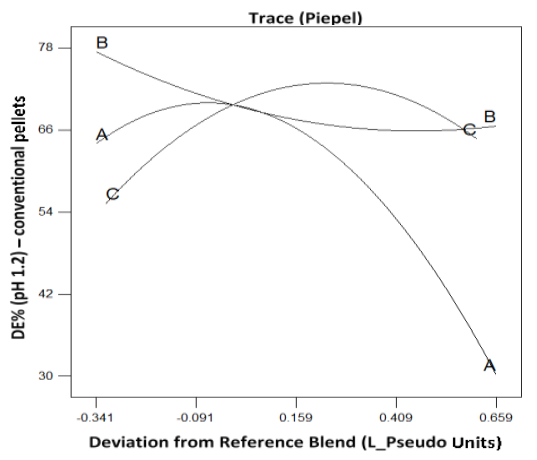

Figure 11. Contour and trace plots of dissolution efficiency for (a) mini and (b) conventional pellets at pH 1.2. 

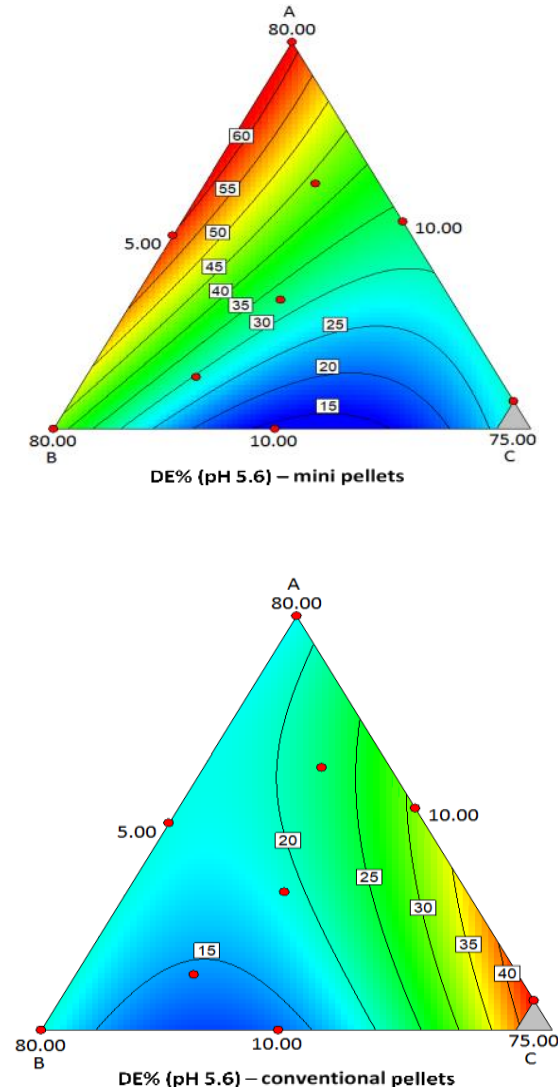

(a)

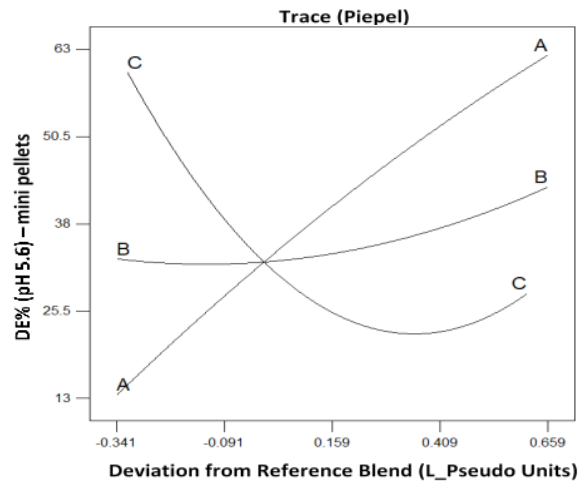

(b)

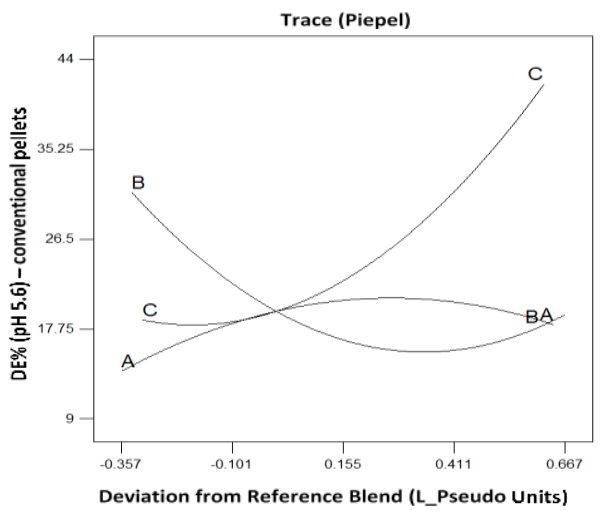

Figure 12. Contour and trace plots of dissolution efficiency for (a) mini and (b) conventional pellets at pH 5.6.

In-Vitro Release Mechanisms

Further elucidation of the release mechanisms is provided by examining the values of the ' $b$ ' parameter from the Weibull model, as presented in Table 8 for release at $\mathrm{pH} 1.2$ and pH 5.6 for mini and conventional pellets. The generally high $\mathrm{R}^{2}$ values of the non-linear regressions indicate good model fitting. Considering the release times recorded at $\mathrm{pH} 1.2$, it can be seen from Table 8 that, for the mini pellet batches A, B, C and G and the conventional pellet batches A, E, F, G, H, and I, the parameter ' $b$ ' is $>1.0$. This indicates a sigmoidal curve, i.e., a small initial increase up to the infection point (not visible in the curves since it occurs within in the first $15 \mathrm{~min}$ ) and followed thereafter by an increase asymptotically to maximum.

Concerning release from the mini pellet batches at $\mathrm{pH} 5.6$, the data in Table 8 show that, with the exception of batches $\mathrm{G}$ and $\mathrm{D}$, ' $b$ ' parameter values ranged between 0.69 and 0.75 , which indicates normal (Fickian) diffusion. Batch $\mathrm{G}$ presented $b=0.63$, which indicates release by diffusion in a disordered matrix structure. This may be attributed to the high MCC or low CHS2 (10\%) resulting in a non-homogenous structure and possible existence of 'dry' regions inside the gel during dissolution. Batch D showed $b=0.76$, which indicates Fickian diffusion enhanced by a further release mechanism. This may be attributed to the high drug content and erosion during dissolution (Figure 10d). Regarding release at $\mathrm{pH} 5.6$ for the conventional pellets, it can be seen from Table 8 that the ' $b$ ' values varied between 0.69 and 0.96 , which implies operation of normal or combined diffusion. However, because less than $50 \%$ of the drug was released in the 8 -h test period, a detailed analysis of the mechanisms involved would be unreliable and of limited value. 
Table 8. Weibull equation parameters (mean $\pm S D, n=3$ ) for the dissolution of mini and conventional pellets at $\mathrm{pH} 1.2$ and 5.6.

\begin{tabular}{|c|c|c|c|c|c|c|c|c|c|c|c|c|}
\hline \multirow{3}{*}{$\begin{array}{l}\text { Batch } \\
\text { Code }\end{array}$} & \multicolumn{6}{|c|}{ Parameters at $\mathrm{pH} 1.2$} & \multicolumn{6}{|c|}{ Parameters at pH 5.6} \\
\hline & \multicolumn{3}{|c|}{ Mini Pellets } & \multicolumn{3}{|c|}{ Conventional Pellets } & \multicolumn{3}{|c|}{ Mini Pellets } & \multicolumn{3}{|c|}{ Conventional Pellets } \\
\hline & $b^{\#}$ & td & $\mathbf{R}^{2}$ & $b$ & td & $\mathbf{R}^{2}$ & $b$ & td & $\mathbf{R}^{2}$ & $b$ & td & $\mathbf{R}^{2}$ \\
\hline $\mathrm{A}$ & 1.16 & $40.3 \pm 1.7$ & 0.996 & 1.14 & $36.8 \pm 1.5$ & 0.993 & 0.73 & $116.2 \pm 1.9$ & 0.969 & 0.71 & $107.1 \pm 1.2$ & 0.990 \\
\hline B & 1.05 & $81.3 \pm 1.1$ & 0.988 & 0.78 & $83.4 \pm 2.6$ & 0.982 & 0.69 & $42.3 \pm 1.2$ & 0.879 & 0.67 & $32.2 \pm 0.7$ & 0.968 \\
\hline $\mathrm{C}$ & 1.15 & $79.2 \pm 0.6$ & 0.992 & 0.96 & $69.7 \pm 1.9$ & 0.985 & 0.70 & $121.1 \pm 2.6$ & 0.980 & 0.85 & $120.6 \pm 1.9$ & 0.992 \\
\hline $\mathrm{D}$ & 0.74 & $26.9 \pm 2.3$ & 0.912 & 0.74 & $26.9 \pm 2.9$ & 0.912 & 0.76 & $105.9 \pm 1.8$ & 0.938 & 0.79 & $88.2 \pm 2.1$ & 0.994 \\
\hline $\mathrm{E}$ & 0.96 & $26.9 \pm 1.4$ & 0.997 & 1.36 & $42.7 \pm 3.5$ & 0.981 & 0.75 & $127.9 \pm 1.7$ & 0.931 & 0.70 & $114.4 \pm 1.7$ & 0.963 \\
\hline $\mathrm{F}$ & 0.69 & $41.9 \pm 2.5$ & 0.973 & 1.10 & $55.8 \pm 2.7$ & 0.987 & 0.74 & $73.8 \pm 0.9$ & 0.915 & 0.76 & $59.2 \pm 1.1$ & 0.956 \\
\hline G & 1.12 & $56.1 \pm 3.2$ & 0.987 & 1.10 & $51.0 \pm 2.3$ & 0.989 & 0.63 & $111.2 \pm 1.4$ & 0.838 & 0.79 & $64.6 \pm 0.3$ & 0.972 \\
\hline $\mathrm{H}$ & 0.70 & $18.7 \pm 1.3$ & 0.921 & 0.99 & $55.6 \pm 2.3$ & 0.991 & 0.69 & $112.2 \pm 1.8$ & 0.935 & 0.78 & $104.3 \pm 1.3$ & 0.970 \\
\hline I & 0.81 & $19.5 \pm 2.1$ & 0.981 & 1.18 & $33.1 \pm 1.8$ & 0.981 & 0.69 & $96.1 \pm 1.4$ & 0.962 & 0.96 & $118.2 \pm 1.8$ & 0.991 \\
\hline
\end{tabular}

\subsection{Optimization of Formulations}

The numerical optimization was based on the modulation of the parameters $\mathrm{e}_{R}(>0.30)$ and flowability (maximize) for optimal technological properties and release as follows. For fast release in $\mathrm{pH} 1.2$ solution, the $\mathrm{DE} \%$ was maximized and the td was minimized. For extended release, $\mathrm{DE} \%$ in pH 1.2 was minimized. Release within $2 \mathrm{~h}$ in pH 5.6 was set to $60 \%$, and release within $8 \mathrm{~h}$ at pH 5.6 was maximized. As seen from the regression analysis results in Table 5, the above parameters were described by statistically significant models with high values of fitting indices. Therefore, reliable prediction and optimization of the formulations with optimal technological performance and fast or extended release can be computed. The results of the numerical optimization are presented in Table 9 as desirability values for fast (A) and extended release (B). Due to the poor release from the conventional size pellets at $\mathrm{pH}$ 5.6, optimization is presented only for release at $\mathrm{pH}$ 1.2. 
Table 9. Desirability values as computed by numerical optimization for fast (A) and extended release (B) pellets (Criteria for $\mathrm{e}_{\mathrm{R}}$, Flowability, $\mathrm{DE} \%$, and td are described in the text. Drug content was set to target levels shown in the fourth column).

\begin{tabular}{|c|c|c|c|c|c|c|c|c|c|}
\hline \multicolumn{10}{|c|}{ A. Numerical Optimization Solutions for Instant Release } \\
\hline Pellet Size & CHS2 & MCC & Drug & $\mathbf{e}_{\mathbf{R}}$ & Flowability & $\mathrm{DE} \%$ & $\operatorname{td}(\mathrm{pH} 1.2)$ & & esirability \\
\hline \multirow{8}{*}{ Mini Pellets } & 10.55 & 79.45 & 5.0 & 0.33 & 2.70 & 63.97 & 47.94 & & 0.925 \\
\hline & 25.84 & 59.16 & 10.0 & 0.34 & 2.53 & 58.51 & 36.77 & & 0.914 \\
\hline & 35.04 & 44.96 & 15.0 & 0.33 & 2.40 & 64.30 & 32.39 & & 0.925 \\
\hline & 37.71 & 37.29 & 20.0 & 0.32 & 2.32 & 70.44 & 30.06 & & 0.934 \\
\hline & 36.34 & 33.66 & 25.0 & 0.32 & 2.27 & 74.57 & 28.91 & & 0.932 \\
\hline & 36.35 & 28.65 & 30.0 & 0.30 & 2.21 & 77.36 & 26.25 & & 0.926 \\
\hline & 32.14 & 27.86 & 35.0 & 0.30 & 2.18 & 77.60 & 28.12 & & 0.919 \\
\hline & 27.74 & 27.26 & 40.0 & 0.30 & 2.15 & 75.72 & 32.11 & & 0.909 \\
\hline \multirow{8}{*}{ Conventional } & 46.81 & 43.19 & 5.0 & 0.40 & 1.95 & 54.33 & 52.51 & & 0.889 \\
\hline & 43.41 & 41.59 & 10.0 & 0.40 & 1.92 & 59.17 & 50.24 & & 0.902 \\
\hline & 39.24 & 40.76 & 15.0 & 0.40 & 1.88 & 63.37 & 48.28 & & 0.910 \\
\hline & 34.75 & 40.25 & 20.0 & 0.40 & 1.85 & 66.55 & 47.12 & & 0.914 \\
\hline & 30.10 & 39.90 & 25.0 & 0.40 & 1.81 & 68.57 & 46.94 & & 0.912 \\
\hline & 31.80 & 33.20 & 30.0 & 0.37 & 1.75 & 70.54 & 44.38 & & 0.909 \\
\hline & 32.91 & 27.09 & 35.0 & 0.34 & 1.68 & 72.69 & 41.08 & & 0.904 \\
\hline & 28.45 & 26.55 & 40.0 & 0.33 & 1.65 & 73.05 & 40.73 & & 0.897 \\
\hline \multicolumn{10}{|c|}{$\begin{array}{l}\text { B. Numerical Optimization Solutions for Extended Release } \\
\text { Criteria: Shape index }>0.30 \text {. Flowability maximize. DE\% at pH } 1.2 \text { maximize. Release in } \mathrm{pH} 5.6 \text { in less than } 2 \mathrm{~h} \text {. } \\
\text { Release in } 5.6 \text { at } 8 \text { h more than } 70 \% \text {. Drug content set to different target levels (column } 4 \text { ). }\end{array}$} \\
\hline \multirow{3}{*}{ Mini Pellets } & CHS2 & MCC & Drug & $\mathbf{e}_{\mathbf{R}}$ & Flowability & DE\% & $\begin{array}{c}\text { Release } \\
(2 \mathrm{~h})\end{array}$ & $\begin{array}{c}\text { Release } \\
(8 \mathrm{~h})\end{array}$ & Desirability \\
\hline & 46.02 & 43.98 & 5.0 & 0.30 & 1.71 & 49.9 & 60.0 & 93.3 & 0.857 \\
\hline & 47.32 & 37.68 & 10.0 & 0.33 & 1.61 & 54.0 & 53.1 & 85.4 & 0.726 \\
\hline
\end{tabular}

Considering optimization at $\mathrm{pH} 1.2$ for different preset drug levels, it can be seen that high values of desirability function above 0.919 (in a scale 0 to 1 ) were obtained for drug levels up to $40 \%$. These represented pellets with acceptable shape $\left(e_{R}>0.30\right)$ and flowability $(>2.15 \mathrm{~g} / \mathrm{min})$ that released drugs with dissolution efficiency between $63.97 \%$ and $77.60 \%$ for mini pellets and $54.33 \%$ to $73.05 \%$ for conventional pellets within a time-scale of 28.12 to $47.94 \mathrm{~min}$ and 40.73 to $52.51 \mathrm{~min}$, respectively. Considering optimization at $\mathrm{pH} 5.6$, it can be seen that good values of desirability function of 0.857 and 0.726 were obtained for pellet formulations with $5 \%$ or $10 \%$ drug content, with CHS2\%/MCC $\% / \mathrm{PXC} \%$ compositions of 46.0/43.98/5.0 and 47.3/37.7/10.0, respectively (the analysis did not give meaningful results for drug levels exceeding 10\%). These showed DE\% values of less than $49.9 \%$ and $54 \%$ at $\mathrm{pH}$ 1.2 and $\mathrm{pH} 5.6$, respectively, and released less than $60 \%$ and $53.1 \%$ within $2 \mathrm{~h}$, and $93.3 \%$ and $85.4 \%$ after $8 \mathrm{~h}$. Therefore, these formulations could be considered suitable for the further development of extended-release chitosan pellets of a poorly soluble non-interacting drug.

\section{Conclusions}

Medium viscosity chitosan grade prompted greater 'apparent' solubility improvement of piroxicam in both pH 1.2 and deionized water. However, due to the coherent gel consistency, drug release from conventional-sized pellets obtained with a 1-mm extrusion screen was extremely slow and excluded any possibility for practical use. On the contrary, use of mini pellets obtained with a $0.5 \mathrm{~mm}$ extrusion screen gave complete and extended release in deionized water following Fickian diffusion, as indicated by analysis of 8-h release data, according to the Weibull kinetic model. Batches of mini 
pellets prepared with a chitosan/microcrystalline cellulose ratio $\geq 2$ and drug content up to $21.25 \%$ showed the best extended release that was nearly complete after $8 \mathrm{~h}$ and could be potentially used for further development. Optimization of the results of technological properties and drug release pointed out optimal formulations for fast-release mini pellets with CHS between $10.55 \%$ and $37.71 \%$, MCC between $27.26 \%$ and $79.45 \%$, and drugs up to $40 \%$. For extended release, the optimal formulations were mini pellets with $5 \%$ drug, CHS2 $=46.02 \%$ and $\mathrm{MCC} \%=43.98 \%$, and mini pellets with $10 \%$ drug, CHS2 $=47.32 \%$, and $\mathrm{MCC}=37.68 \%$.

Author Contributions: Conceptualization, I.N. and P.G. Methodology, I.N. Software, I.N. and I.P. Experimentation and data processing, P.G., I.P. and N.K. Writing-original draft preparation, I.P., P.G. and I.N.

Funding: The purchase of Raman spectrometer was funded by the Research Program for the Development of Industrial Research in Greece and Technology Growth (NSRF2013) granted to VIANEX SA, Athens, Greece to whom we are grateful.

Conflicts of Interest: The authors declare no conflict of interest.

\section{References}

1. Ghebre-Selassie, I.; Martin, C. Pharmaceutical Extrusion Technology; Taylor \& Francis: Abingdon, UK, 2003.

2. Nikolakakis, I.; Partheniadis, I. Self-Emulsifying Granules and Pellets: Composition and Formation Mechanisms for Instant or Controlled Release. Pharmaceutics 2017, 9, 50. [CrossRef] [PubMed]

3. Akhgari, A.; Sadeghi, F.; Garekani, H.A. Combination of time-dependent and pH-dependent polymethacrylates as a single coating formulation for colonic delivery of indomethacin pellets. Int. J. Pharm. 2006, 320, 137-142. [CrossRef] [PubMed]

4. Prabhakaran, L.; Prushothaman, M.; Sriganesan, P. Pharmaceutical micropellets: An overview. Pharm. Rev. 2009, 7, 727-731.

5. Yoburn, B.C.; Chen, J.; Huang, T.; Inturrisi, C.E. Pharmacokinetics and pharmacodynamics of subcutaneous morphine pellets in the rat. J. Pharmacol. Exp. Ther. 1985, 235, 282-286. [PubMed]

6. Muley, S.; Nandgude, T.; Poddar, S. Extrusion-spheronization a promising pelletization technique: In-depth review. Asian J. Pharm. Sci. 2016, 11, 684-699. [CrossRef]

7. Reddy, P.N.S.; De, A.; Nagasamy Venkatesh, D. Pelletization process and techniques. Pharma Times 2015, 47, 22-27.

8. Pałkowski, Ł.; Karolak, M.; Kubiak, B.; Błaszczyński, J.; Słowiński, R.; Thommes, M.; Kleinebudde, P.; Krysiński, J. Optimization of pellets manufacturing process using rough set theory. Eur. J. Pharm. Sciences 2018, 124, 295-303. [CrossRef] [PubMed]

9. Sarkar, S.; Liew, C.V.; Soh, J.L.P.; Heng, P.W.S.; Wong, T.W. Microcrystalline cellulose: An overview. In Functional Polymeric Composites: Macro Nanoscales; Apple Academic Press: New York, NY, USA, 2017. [CrossRef]

10. Newton, J.M. Extrusion and extruders. In Encyclopedia of Pharmaceutical Technology; Swarbrick, J., Boylan, J.C., Eds.; Marcel Dekker Inc.: New York, NY, USA; Basel, Switzerland, 2002; pp. 1220-1236.

11. Shah, R.D.; Kabadi, M.; Pope, D.G.; Augsburger, L.L. Physico-mechanical characterization of the extrusion-spheronization process. Part II: Rheological determinants for successful extrusion and spheronization. Pharm. Res. 1995, 12, 496-507. [CrossRef] [PubMed]

12. Sonaglio, D.; Bataille, B.; Ortigosa, C.; Jacob, M. Factorial design in the feasibility of producing Microcel MC 101 pellets by extrusion/spheronization. Int. J. Pharm. 1995, 115, 53-60. [CrossRef]

13. Okada, S.; Nakahara, H.; Isaka, H. Adsorption of drugs on microcrystalline cellulose suspended in aqueous solutions. Chem. Pharm. Bull. 1987, 35, 761-768. [CrossRef]

14. Awa, K.; Shinzawa, H.; Ozaki, Y. The effect of microcrystalline cellulose crystallinity on the hydrophilic property of tablets and the hydrolysis of acetylsalicylic acid as active pharmaceutical ingredient inside tablets. AAPS PharmSciTech 2015, 16, 865-870. [CrossRef]

15. Basit, A.W.; Newton, J.M.; Lacey, L.F. Formulation of ranitidine pellets by extrusion-spheronization with little or no microcrystalline cellulose. Pharm. Dev. Technol. 1999, 4, 499-505. [CrossRef]

16. Brandl, M.; Magill, A.; Rudraraju, V.; Gordon, M.S. Approaches for improving the stability of ketorolac in powder blends. J. Pharm. Sci. 1995, 84, 1151-1153. [CrossRef] [PubMed] 
17. O'Connor, R.E.; Schwartz, J.B. Spheronization II: Drug Release from Drug-Diluent Mixtures. Drug Dev. Ind. Pharm. 1985, 11, 1837-1857. [CrossRef]

18. Otero-Espinar, F.J.; Luzardo-Alvarez, A.; Blanco-Méndez, J. Non-MCC materials as extrusion-spheronization aids in pellets production. J. Drug Deliv. Sci. Technol. 2010, 20, 303-318. [CrossRef]

19. Goskonda, S.R.; Hileman, G.A.; Upadrashta, S.M. Controlled release pellets by extrusion-spheronization. Int. J. Pharm. 1994, 111, 89-97. [CrossRef]

20. Cheung, R.C.; Ng, T.B.; Wong, J.H.; Chan, W.Y. Chitosan: An Update on Potential Biomedical and Pharmaceutical Applications. Mar. Drugs 2015, 13, 5156-5186. [CrossRef]

21. Muzzarelli, R.A.A. Chitins and chitosans as immunoadjuvants and non-allergenic drug carriers. Mar. Drugs 2010, 8, 292-312. [CrossRef]

22. Castellsague, J.; Riera-Guardia, N.; Calingaert, B.; Varas-Lorenzo, C.; Fourrier-Reglat, A.; Nicotra, F.; Sturkenboom, M.; Perez-Gutthann, S. Individual NSAIDs and upper gastrointestinal complications: A systematic review and meta-analysis of observational studies (the SOS project). Drug Saf. 2012, 35, 1127-1146. [CrossRef]

23. Imai, T.; Shiraishi, S.; Saitô, H.; Otagiri, M. Interaction of indomethacin with low molecular weight chitosan, and improvements of some pharmaceutical properties of indomethacin by low molecular weight chitosans. Int. J. Pharm. 1991, 67, 11-20. [CrossRef]

24. Ito, M.; Ban, A.; Ishihara, M. Anti-ulcer effects of chitin and chitosan, healthy foods, in rats. Jpn. J. Pharmacol. 2000, 82, 218-225. [CrossRef]

25. Zerrouk, N.; Mennini, N.; Maestrelli, F.; Chemtob, C.; Mura, P. Comparison of the effect of chitosan and polyvinylpyrrolidone on dissolution properties and analgesic effect of naproxen. Eur. J. Pharm. Biopharm. 2004, 57, 93-99. [CrossRef]

26. Charoenthai, N.; Kleinebudde, P.; Puttipipatkhachorn, S. Use of chitosan-alginate as alternative pelletization aid to microcrystalline cellulose in extrusion/spheronization. J. Pharm. Sci. 2007, 96, 2469-2484. [CrossRef] [PubMed]

27. Sakkinen, M.; Seppala, U.; Heinanen, P.; Marvola, M. In vitro evaluation of microcrystalline chitosan (MCCh) as gel-forming excipient in matrix granules. Eur. J. Pharm. Biopharm. 2002, 54, 33-40. [CrossRef]

28. Bernkop-Schnurch, A.; Dunnhaupt, S. Chitosan-based drug delivery systems. Eur. J. Pharm. Biopharm. 2012, 81, 463-469. [CrossRef] [PubMed]

29. Bonferoni, M.C.; Rossi, S.; Ferrari, F.; Bertoni, M.; Bolhuis, G.K.; Caramella, C. On the employment of $\lambda$ carrageenan in a matrix system. III. Optimization of a $\lambda$ carrageenan-HPMC hydrophilic matrix. J. Controll. Release 1998, 51, 231-239. [CrossRef]

30. Tapia, C.; Buckton, G.; Newton, J.M. Factors influencing the mechanism of release from sustained release matrix pellets, produced by extrusion/spheronisation. Int. J. Pharm. 1993, 92, 211-218. [CrossRef]

31. Agrawal, A.M.; Manek, R.V.; Kolling, W.M.; Neau, S.H. Water distribution studies within microcrystalline cellulose and chitosan using differential scanning calorimetry and dynamic vapor sorption analysis. J. Pharm. Sci. 2004, 93, 1766-1779. [CrossRef]

32. Izdes, S.; Orhun, S.; Turanli, S.; Erkilic, E.; Kanbak, O. The effects of preoperative inflammation on the analgesic efficacy of intraarticular piroxicam for outpatient knee arthroscopy. Anesth. Analg. 2003, 97, 1016-1019. [CrossRef] [PubMed]

33. Mohammadi-Samani, S.; Zojaji, S.; Entezar-Almahdi, E. Piroxicam loaded solid lipid nanoparticles for topical delivery: Preparation, characterization and in vitro permeation assessment. J. Drug Deliv. Sci. Technol. 2018, 47, 427-433. [CrossRef]

34. Shohin, I.E.; Kulinich, J.I.; Ramenskaya, G.V.; Abrahamsson, B.; Kopp, S.; Langguth, P.; Polli, J.E.; Shah, V.P.; Groot, D.W.; Barends, D.M.; et al. Biowaiver monographs for immediate release solid oral dosage forms: Piroxicam. J. Pharm. Sci. 2014, 103, 367-377. [CrossRef] [PubMed]

35. Paaver, U.; Lust, A.; Mirza, S.; Rantanen, J.; Veski, P.; Heinamaki, J.; Kogermann, K. Insight into the solubility and dissolution behavior of piroxicam anhydrate and monohydrate forms. Int. J. Pharm. 2012, 431, 111-119. [CrossRef] [PubMed]

36. Sanka, K.; Bandari, S.; Jukanti, R.; Veerareddy, P. Colon-Specific Microparticles of Piroxicam: Formulation and Optimization Using 32 Factorial Design. J. Disper. Sci. Technol. 2011, 32, 1396-1403. [CrossRef]

37. Abdulkarim, M.F.; Abdullah, G.Z.; Chitneni, M.; Salman, I.M.; Ameer, O.Z.; Yam, M.F.; Mahdi, E.S.; Sattar, M.A.; Basri, M.; Noor, A.M. Topical piroxicam in vitro release and in vivo anti-inflammatory and analgesic effects from palm oil esters-based nanocream. Int. J. Nanomed. 2010, 5, 915-924. [CrossRef] [PubMed] 
38. Mohammed, M.A.; Syeda, J.T.M.; Wasan, K.M.; Wasan, E.K. An Overview of Chitosan Nanoparticles and Its Application in Non-Parenteral Drug Delivery. Pharmaceutics 2017, 9, 53. [CrossRef]

39. Papadopoulou, V.; Kosmidis, K.; Vlachou, M.; Macheras, P. On the use of the Weibull function for the discernment of drug release mechanisms. Int. J. Pharm. 2006, 309, 44-50. [CrossRef] [PubMed]

40. Santos, H.; Veiga, F.; Pina, M.; Podczeck, F.; Sousa, J. Physical properties of chitosan pellets produced by extrusion-spheronisation: Influence of formulation variables. Int. J. Pharm. 2002, 246, 153-169. [CrossRef]

41. Matsaridou, I.; Barmpalexis, P.; Salis, A.; Nikolakakis, I. The influence of surfactant HLB and oil/surfactant ratio on the formation and properties of self-emulsifying pellets and microemulsion reconstitution. AAPS PharmSciTech 2012, 13, 1319-1330. [CrossRef]

42. Podczeck, F.; Newton, J.M. A Shape Factor to Characterize the Quality of Spheroids. J. Pharm. Pharmacol. 1994, 46, 82-85. [CrossRef]

43. General Chapters: <1174> Powder Flow. Available online: http://www.pharmacopeia.cn/v29240/ usp29nf24s0_c1174.html (accessed on 2 November 2018).

44. Langenbucher, F. Linearization of dissolution rate curves by the Weibull distribution. J. Pharm. Pharmacol. 1972, 24, 979-981. [CrossRef]

45. Myers, R.H.; Montgomery, D.C. Process and Product Optimization Using Designed Experiments; Wiley Series in Probability and Statistics; John Wiley and Sons: New York, NY, USA, 1995; pp. 590-591.

46. Drebushchak, V.A.; Shakhtshneider, T.P.; Apenina, S.A.; Medvedeva, A.S.; Safronova, L.P.; Boldyrev, V.V. Thermoanalyticalinvestigation of drug-excipient interaction. J. Therm. Anal. Calorim. 2006, 86, 303-309. [CrossRef]

47. Ivanova, D.; Deneva, V.; Nedeltcheva, D.; Kamounah, F.S.; Gergov, G.; Hansen, P.E.; Kawauchid, S.; Antonova, L. Tautomeric transformations of piroxicam in solution: A combined experimental and theoretical study. RSC Adv. 2015, 5, 31852-31860. [CrossRef]

48. Oka, S.; Emady, H.; Kašpar, O.; Tokárová, V.; Muzzio, F.; Štěpánek, F.; Ramachandran, R. The effects of improper mixing and preferential wetting of active and excipient ingredients on content uniformity in high shear wet granulation. Powder Technol. 2015, 278, 266-277. [CrossRef]

49. Tang, P.; Puri, V.M. Methods for Minimizing Segregation: A Review. Part. Sci. Technol. 2004, 22, $321-337$. [CrossRef]

50. Balaxi, M.; Nikolakakis, I.; Kachrimanis, K.; Malamataris, S. Combined effects of wetting, drying, and microcrystalline cellulose type on the mechanical strength and disintegration of pellets. J. Pharm. Sci. 2009, 98, 676-689. [CrossRef]

51. Harwood, C.F.; Pilpel, N. The flow of granular solids through circular orifices. J. Pharm. Pharmacol. 1969, 21, 721-730. [CrossRef]

52. Kogermann, K.; Aaltonen, J.; Strachan, C.J.; Pollanen, K.; Veski, P.; Heinamaki, J.; Yliruusi, J.; Rantanen, J. Qualitative in situ analysis of multiple solid-state forms using spectroscopy and partial least squares discriminant modeling. J. Pharm. Sci. 2007, 96, 1802-1820. [CrossRef]

53. Liu, G.; Hansen, T.B.; Qu, H.; Yang, M.; Pajander, J.P.; Rantanen, J.; Christensen, L.P. Crystallization of Piroxicam Solid Forms and the Effects of Additives. Chem. Eng. Technol. 2014, 37, 1297-1304. [CrossRef]

54. International Center for Diffraction Data. Standard Cards of Piroxicam, PDF Numbers 40-1982 and 44-1839; ICDD: Newtown Square, PA, USA, 2003.

55. Albertini, B.; Cavallari, C.; Passerini, N. Evaluation of b-lactose, PVP K12 and PVP K90 as excipients to prepare piroxicam granules using two wet granulation techniques. Eur. J. Pharm. Biopharm. 2003, 56, 479-487. [CrossRef]

56. Khattab, A.; Zaki, N. Optimization and Evaluation of Gastroretentive Ranitidine $\mathrm{HCl}$ Microspheres by Using Factorial Design with Improved Bioavailability and Mucosal Integrity in Ulcer Model. AAPS PharmSciTech 2017, 18, 957-973. [CrossRef] [PubMed]

57. Nejati, L.; Kalantari, F.; Bavarsad, N.; Saremnejad, F.; Moghaddam, P.T.; Akhgari, A. Investigation of using pectin and chitosan as natural excipients in pellet formulation. Int. J. Biol. Macromol. 2018, 120, 1208-1215. [CrossRef] [PubMed]

(C) 2019 by the authors. Licensee MDPI, Basel, Switzerland. This article is an open access article distributed under the terms and conditions of the Creative Commons Attribution (CC BY) license (http://creativecommons.org/licenses/by/4.0/). 